\title{
The Use of Remote Sensing Data to Estimate Land Area with Forest Vegetation Cover in the Context of Selected Forest Definitions
}

\author{
Tomasz Hycza (D), Agnieszka Kamińska (1) and Krzysztof Stereńczak*(1) \\ The Department of Geomatics, The Forest Research Institute, Sękocin Stary, Braci Leśnej 3, 05-090 Raszyn, Poland; \\ t.hycza@ibles.waw.pl (T.H.); a.kaminska@ibles.waw.pl (A.K.) \\ * Correspondence: k.sterenczak@ibles.waw.pl; Tel.: +48-22-7150-323
}

check for updates

Citation: Hycza, T.; Kamińska, A.; Stereńczak, K. The Use of Remote Sensing Data to Estimate Land Area with Forest Vegetation Cover in the Context of Selected Forest Definitions. Forests 2021, 12, 1489.

https://doi.org/10.3390/f12111489

Academic Editor: Mark Vanderwel

Received: 5 October 2021

Accepted: 26 October 2021

Published: 29 October 2021

Publisher's Note: MDPI stays neutral with regard to jurisdictional claims in published maps and institutional affiliations.

Copyright: (C) 2021 by the authors. Licensee MDPI, Basel, Switzerland. This article is an open access article distributed under the terms and conditions of the Creative Commons Attribution (CC BY) license (https:/ / creativecommons.org/licenses/by/ $4.0 /)$.

\begin{abstract}
Background: Like many other countries, Poland is obliged to report forest area to the Climate Convention (UNFCCC Kyoto Protocol) and the Food and Agriculture Organization of the United Nations (FAO/UN). Differences between national and international forest definitions lead to differences between actual and reported forest area. Remote sensing is a useful tool for estimating forest area for reporting purposes. One of the most important parts of the estimation is the choice of a basal area to calculate the percentage of vegetation cover. (2) Methods: Height, crown projection area, and minimum complex area were used to classify the area with forest vegetation. Percentage canopy cover was determined using three different methods based on segmentation polygons, triangular grid and canopy height model pixels. The accuracy of the above methods was verified by manual vectorization performed on a selected set of test plots in the Milicz study area according to the international definitions. The differences were examined using three statistical metrics. (3) Conclusions: This paper compares for the first time methods for determining the area for which canopy cover is calculated (using data from (ALS) and discusses the differences between them in the context of accuracy (the correspondence between the results and the reference data) and the complexity of the process (time and effort required to perform the analysis). This is important in the context of reporting, estimating carbon stocks and biodiversity to mitigate the effects of climate change. Method 2 proved to be the most accurate method, Method 1 was found to be the worst option. Accuracy was better in the case of the Kyoto Protocol definition.
\end{abstract}

Keywords: lidar; forest vegetation; remote sensing; forest definition; reporting

\section{Background}

Throughout the world there are a number of forest definitions. Some of these are formulated in national law and apply only to the forests of that state, while others are international. The differences in forest definitions arise from the different characteristics of forest vegetation around the world and the different forms of forest management [1]. In addition, the differences in forest area under different definitions are influenced by the geometric characteristics of trees [2-6]. There are also some economic and political reasons why different countries consider certain areas to be forests [7].

One consequence of using different definitions is the discrepancy in area statistics between individual countries or continents. Depending on the data and methodology, the global rainforest area ranges from 1090 to 1220 million hectares, in Africa from 185 to 215 million hectares, in Asia from 235 to 275 million hectares, and in South America from 670 to 730 million hectares (Table 1) [8]. The difference in estimated forest area for 19 European countries was 13\% [2], and the difference in area affected by deforestation in Indonesia during 2000-2009 was 27\% [6]. These reported differences were the result of different definitions and methods used. The problem is exacerbated when a country 
is required to report its forest area to an international organization and forest definitions differ significantly.

Table 1. Tropical forest area $\left(10^{3} \mathrm{ha}\right)$ estimates of Central and West Africa Central America, Caribbean and South America from TREES project, FAO FRA 90 (FAO, 1993) and IUCN according to Mayeux (et al., 1998) [8].

\begin{tabular}{|c|c|c|c|c|c|c|}
\hline & Land Area & $\begin{array}{c}\text { Evergreen and } \\
\text { Tropical Rain } \\
\text { Forest }\end{array}$ & $\begin{array}{c}\text { Tropical Rain } \\
\text { Forest }\end{array}$ & $\begin{array}{l}\text { Wet, Moist and } \\
\text { Mountain } \\
\text { Forest }\end{array}$ & $\begin{array}{c}\text { Closed } \\
\text { Broadleaved } \\
\text { Forest }\end{array}$ & Closed Forest \\
\hline Central Africa & 398,320 & 183,967 & 78,821 & 202,456 & 158,300 & 185,802 \\
\hline West Africa & 203,803 & 17,859 & 3231 & 52,223 & 15,569 & 13,470 \\
\hline Total Africa & 602,123 & 201,826 & 82,052 & 254,679 & 173,869 & 199,273 \\
\hline $\begin{array}{l}\text { Central } \\
\text { America }\end{array}$ & 50,977 & 18,029 & 11,957 & 21,525 & 17,499 & 22,649 \\
\hline $\begin{array}{l}\text { Caribbean- } \\
\text { Mexico }\end{array}$ & 202,934 & 32,858 & 267 & 746,763 & 10,130 & 54,321 \\
\hline South America & $1,002,297$ & 652,772 & 438,932 & 715,509 & 637,050 & 615,605 \\
\hline
\end{tabular}

For example, Poland, like many other countries, is required to report forest area for the Climate Convention (Kyoto Protocol) and the Food and Agriculture Organization of the United Nations (FAO/UN). Reporting of forest area in Poland is based on data published in the statistical yearbooks "Forestry" and "Environmental Protection" of the Central Statistical Office. Details of the definition of forest area formulated for Poland in the Forest Act (Act on Forests, 1991), FAO/UN [9-11] and the Kyoto Protocol [12] are presented in Table 2 [13-16].

Table 2. Criteria for delimiting forest areas.

\begin{tabular}{cccc}
\hline Variables & Law on Forests-Poland & FAO & Kyoto Protocol \\
\hline Minimum area (ha) & 0.1 & 0.5 & 0.1 \\
Minimum height (m) & - & 5 & 2 \\
Minimum crown coverage (\%) & - & 10 & 10 \\
Width of the forest complex (m) & - & - & 10 \\
\hline Land intended for renovation & yes & yes & yes \\
Land intended for natural & yes & yes & yes \\
succession & yes & yes & yes \\
Hunting plots & yes & yes & yes \\
Christmas tree plantations & no & yes & no \\
Post-agricultural land with & & yes & yo \\
secondary succession & yes & & yo \\
Land related to forest & & &
\end{tabular}

The definition of forest in the 1991 Forestry Act (in Poland) does not require canopy cover or height. However, forest plantations established in state forests are considered successful if crown closure is at least $50 \%$ in the fifth year after regeneration. Conversion of agricultural land to forest land (under the Rural Development Program) occurs when the suitability determined on the basis of land cover is $50 \%$ for land with natural succession or $70 \%$ for artificial afforestation. However, there is still no minimum canopy cover and height required to recognize an area with forest vegetation as forests. Areas with or without forest vegetation may be also excluded or included in the forest area due to their land use. Moreover, there are many such rules that result in the forest area, which varies according 
to the definition used [13-16]. Ultimately, different forest areas are reported even for a single country.

Since the methods used to define a forest area often vary from country to country, it is important to develop a methodology that is as homogeneous/utilitarian as possible. In line with Neef et al. [17], this allows a trade-off between reporting reliability, ecosystem characteristics and social and economic needs.

The simplest methods for estimating forest areas include manual vectorization [18] and NDVI index-based analysis, including change detection analysis performed on multiple images [19]. Statistical estimation methods based on data from regularly distributed sample plots are an important means of estimating forest area in sparsely populated countries with a very high proportion of forested areas, where conventional in-situ inventory in each forest sub-area is simply impossible (e.g., Canada, Russia) [20-26].

Aerial and satellite imagery have been successfully used since the early 2000 s to estimate the area of forested areas with an accuracy of $80 \%$ for forest areas [20-22,27-32], $95 \%$ for secondary forests $[18,19,33-35]$, and $75 \%$ for trees in agricultural areas [36]. Other sophisticated image-based methods include object segmentation and supervised classification [30,35], but few of them consider the geometric features of forest vegetationheight [32,34] and canopy [34] mentioned in the international forest definitions with an overall accuracy of $95 \%$. However, their fractional values ( $1 \mathrm{~m}, 2-20 \%$ cover) do not correspond to the values given in the international forest definitions $(2-5 \mathrm{~m}, 10 \%)$. Although image-based remote sensing technology is very useful for forest area estimation, its full potential has not yet been discovered and there are still many unsolved problems.

Airborne laser scanning data (ALS) provide information on elevation, which is an important variable in forest definition. Currently, up-to-date ALS data are available in many countries worldwide (in Poland within the ISOK project-IT system of Country Shield) and are widely used for remote sensing analysis. Since, at least in Europe, there is already a nearly homogeneous ALS database covering almost all of Europe, it is important to develop automatic methods based specifically on the data from ALS. The use of ALS data makes it possible to achieve or improve the results of forest area estimations [22,26,32,34-37]. Single tree extraction based on airborne laser scanning data (ALS) has been discussed in numerous publications [38-47]. It allows the creation of a vector layer of polygons representing individual trees with the projection area and height. The collection of individual trees allowed the analysis of species and health status at the individual tree level [48]. However, ALS data has its disadvantages as well, e.g., ineffective during heavy rain or low hanging clouds, at high sun angles and reflections, low operating altitude of between 500-2000 m and a decreased ability penetrating very dense/thick forests.

Land use is an important factor responsible for differences in official forest area statistics [5]. However, remote sensing methods can only classify areas in terms of their cover. Unfortunately, it is not possible to determine the land use category according to BDOT (Spatial Object Database) or other national land use databases. There are areas of forest vegetation that are not forest land by various definitions (e.g., post-agricultural areas with secondary succession, swamps, etc.), and forest land that is permanently or temporarily not forested (e.g., areas with intensive forest management-clearcuts, wind damaged or burned areas, etc.). Species composition may also be an important factor, as some countries have plantations of industrial crops that may (or may not) be considered forests for political (rather than ecological) reasons $[4,6]$.

There is currently no consensus on how to determine the area for which tree canopy cover should be calculated [49]. Individual authors have investigated the accuracy of different methods, but none of them have attempted to compare these methods. Eysn et al. [50-52] and Sackov and Kardos [53] used a triangulation-based method that calculated the fraction of tree canopy cover for the area under the canopy of three adjacent trees and the intervening tree. They achieved an accuracy of $96-98.4 \%$ and $93 \%$, respectively. Straub et al. [54] used a grid of squares with a defined mesh area for this purpose and achieved $97.7 \%$ accuracy. Wang et al. [27-29] calculated the percentage of pixels that were above a 
certain threshold using the Canopy Height Model (CHM) in a grid with a defined mesh area. A detailed description of the methods can be found in the "Methods" chapter.

An important part of the remote sensing analysis related to forest area estimation is the accuracy assessment based on inventory data, which may differ significantly due to many factors, e.g., the number and distribution of sample plots, measurement methodology $[3,54]$, or simply due to outdated records in existing databases [13-16,55]. When statistics are used in inventory procedures, sampling and inference methods can also affect estimation results [8]. This approach to collecting reference data is particularly useful in sparsely populated countries with a very high proportion of forest (e.g., Canada, Russia), where the forest area is too large to conduct a full in-situ field inventory. In Poland, the area covered with trees is classified as forest, rather than woodland, when preparing management plans according to the Forest Act (Poland, 1991), and it is based on a field survey of individual stands. Thus, in the case of the reference data, each stand was visited by a forest expert and many different characteristics were estimated or measured in the field (Table 2).

In this paper, we focus on the use of airborne laser scanning data and the estimation of three variables that determine the presence of forest vegetation in the international forest definitions: Elevation, Crown Projection Area and Forest Complex Area, which have not been fully considered in previous works, i.e., [32-34].

The objectives of the study were: (i) to determine the most accurate method, (ii) to calculate the differences between the analyzed methods according to the forest definitions used, (iii) to determine the most effective method in terms of accuracy (the agreement between the results and the reference data) and the complexity of the process (time and effort required to perform the analysis).

This paper compares for the first time methods for determining the area for which canopy cover is calculated (using data from ALS) and discusses the differences between them in terms of accuracy (the correspondence between the results and the reference data) and the complexity of the process (time and effort required to perform the analysis). The area with forest vegetation is a starting point for assessing the forest area according to international definitions, taking into account land use and its future evolution, even without current forest vegetation. This in turn is important in the context of reporting, estimating carbon stocks and biodiversity to mitigate the effects of climate.

\section{Methodology}

\subsection{Study Site}

The study was conducted in the Milicz Forest District (Figure 1), which has a high variability in forest habitat characteristics (Table 3). Forest habitat type is a basic unit in forest habitat classification, which includes all forest areas with similar habitat conditions that have similar production possibilities. The volume of a stand is usually limited to roundwood, measured in cubic meters [56].

The complex is primarily related to the oak-hornbeam habitat. It stretches from Młyńska Woda-a tributary of the Barycz River, to Żmigród, forming a line that is approximately $28 \mathrm{~km}$ long and up to $8 \mathrm{~km}$ wide. Mixed complexes were formed there, in which pine, sometimes spruce, oaks, hornbeams, beeches, birches, as well as ash trees, mainly high and low oak-hornbeam forests and beech trees grow. It is difficult to navigate in these stands due to the dense undergrowth of mountain ash, bird cherry, buckthorn and similar species. The cleanliness of the environment is evidenced by the presence of, among others of Icelandic lung lichen. In some areas, fertile beech forests developed in fertile habitats have survived. Their particularly beautiful fragment near Postolin has been protected since 1962 as a forest and landscape reserve called "Joan's Hill" with an area of 24.6 ha) common beech on the eastern border of this species range. There is also a mixture of oak, ash, pine and spruce. The highest natural value is characterized by the fertile lowland beech and a fragment of acidic lowland beech forest, the liverwort and the eagle-owl fern [56]. 
Table 3. Characteristics of stands in the research area.

\begin{tabular}{|c|c|c|c|c|}
\hline Scheme & Habitat & Species & Age & Volume \\
\hline $\begin{array}{c}\text { Milicz Forest } \\
\text { Department }\end{array}$ & $\begin{array}{c}\text { Fresh } \\
\text { coniferous-19.2\% } \\
(1572.3 \text { ha) } \\
\text { Fresh mixed } \\
\text { coniferous-26.8\% } \\
\text { (2198.1 ha) } \\
\text { Wet mixed } \\
\text { coniferous-5.1\% } \\
\text { (413.9 ha) } \\
\text { Fresh } \\
\text { deciduous-13.5\% } \\
\text { (1105.1 ha) } \\
\text { Fresh mixed } \\
\text { deciduous-13.1\% } \\
\text { (1072.2 ha) } \\
\text { Wet mixed } \\
\text { deciduous- } 4.5 \% \\
\text { (369.4 ha) } \\
\text { Wet deciduous-2.6\% } \\
\text { (216.5 ha) }\end{array}$ & $\begin{array}{c}\text { Pine-74.9\% } \\
(1,973,262.2 \mathrm{ha}) \\
\text { Oak-10.6\% } \\
(279,260.1 \mathrm{ha}) \\
\text { Beech-5.8\% } \\
(152,802.7 \mathrm{ha}) \\
\text { Birch-2\% } \\
(52,690.6 \mathrm{ha}) \\
\text { Alder-4.7\% } \\
(2476.5 \mathrm{ha}) \\
\text { Other-2\% } \\
\text { (52,690.6 ha) }\end{array}$ & $\begin{array}{c}0-20-12 \% \\
(316,143.5 \mathrm{ha}) \\
20-40-15 \% \\
(395,179.4 \mathrm{ha}) \\
40-60-29.6 \% \\
(779,820.6 \mathrm{ha}) \\
60-80-13.6 \% \\
(358,295.9 \mathrm{ha}) \\
80-100-12.7 \% \\
(334,585.2 \mathrm{ha}) \\
>100-15.6 \% \\
(410,986.5 \mathrm{ha})\end{array}$ & $\begin{array}{c}\text { Beech-300 } \\
\mathrm{m}^{3} / \mathrm{ha} \\
\text { Pine-298 } \\
\mathrm{m}^{3} / \mathrm{ha} \\
\text { Alder-285 } \\
\mathrm{m}^{3} / \text { ha } \\
\text { Oak = 275 } \\
\mathrm{m}^{3} / \mathrm{ha}\end{array}$ \\
\hline
\end{tabular}

Many hiking trails run through the Milickie Forests. Wandering them, however, requires a good map, which becomes necessary with the massive presence of mushroom pickers. The red trail from Żmigród through Sułów to Milicz-Karłów, almost exclusively through the forest, is of great importance. Early autumn is an attractive time of the year, when the beautiful colors of the landscapes are given by the clusters of beech trees. The forests of Milicz are distinguished by the great biodiversity of forest animals. You can meet deer, roe deer, fallow deer, wild boar and many other forest inhabitants [56].

\subsection{Remotely Sensed Data}

Airborne laser scanning (ALS) data were collected in August 2015 using a Riegl LMSQ680i laser scanning system with a pulse frequency of $360 \mathrm{kHz}$, resulting in point clouds with an average of 10 pulses $/ \mathrm{m}^{2}$. The mean flight altitude was $550 \mathrm{~m}$ and the field of view of the scanning system was 60 degrees. Together with the point clouds, the data provider created a digital surface model (DSM) and a digital terrain model (DTM) with a spatial resolution of $0.5 \mathrm{~m}$ using TerraSolid software. This DTM was used to normalize all yields from the raw point clouds [57].

Polygon layers representing the crowns of individual trees (with a given area and height) were used for the analyses and were created for the REMBIOFOR project "Remote sensing for determining wood biomass and carbon stocks in forests", which was conducted at the Forest Research Institute from 2014-2018. The segmentation method [58] used the $\mathrm{CHM}$ and adaptive kernel windows in relation to tree height. Taller trees were smoothed with a larger kernel window and shorter trees were smoothed with smaller kernel windows. In total, three groups of trees were defined with respect to height for coniferous and deciduous tree species. Analysis of the results shows that the method works well for dominant trees in the sample and provides a good accuracy (about $80 \%$ ) in correctly detecting trees. When segmentation errors occurred, they did not significantly affect the results, as tree canopy cover was the target and not the exact number of trees. The layer of polygons representing individual tree crowns from segmentation is provided with information on their height and crown projection area in the table of attributes. 


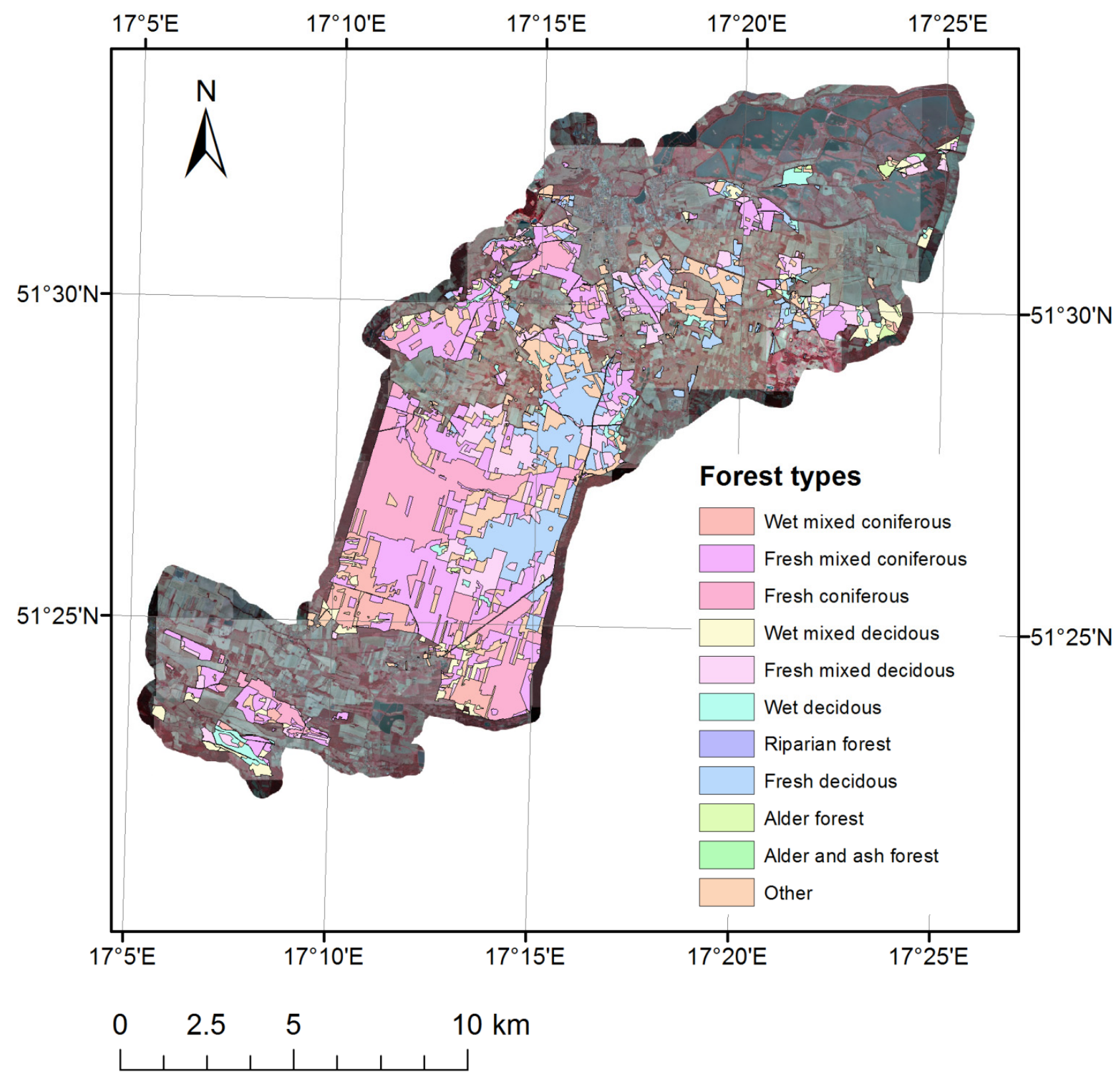

Figure 1. The area of investigation (Forest types and orthophotomap).

\subsection{Methodology in General}

A diagram of the analyses is presented in Figure 2.

Geometric parameters of vegetation (height, area of crown projection, minimum complex area) were used to classify the area with forest vegetation. Land use information was not used. The area with forest vegetation was calculated separately for three methods according to the FAO/UN and Kyoto Protocol definition. The results were compared to the reference data and the differences were assessed using statistical metrics. 


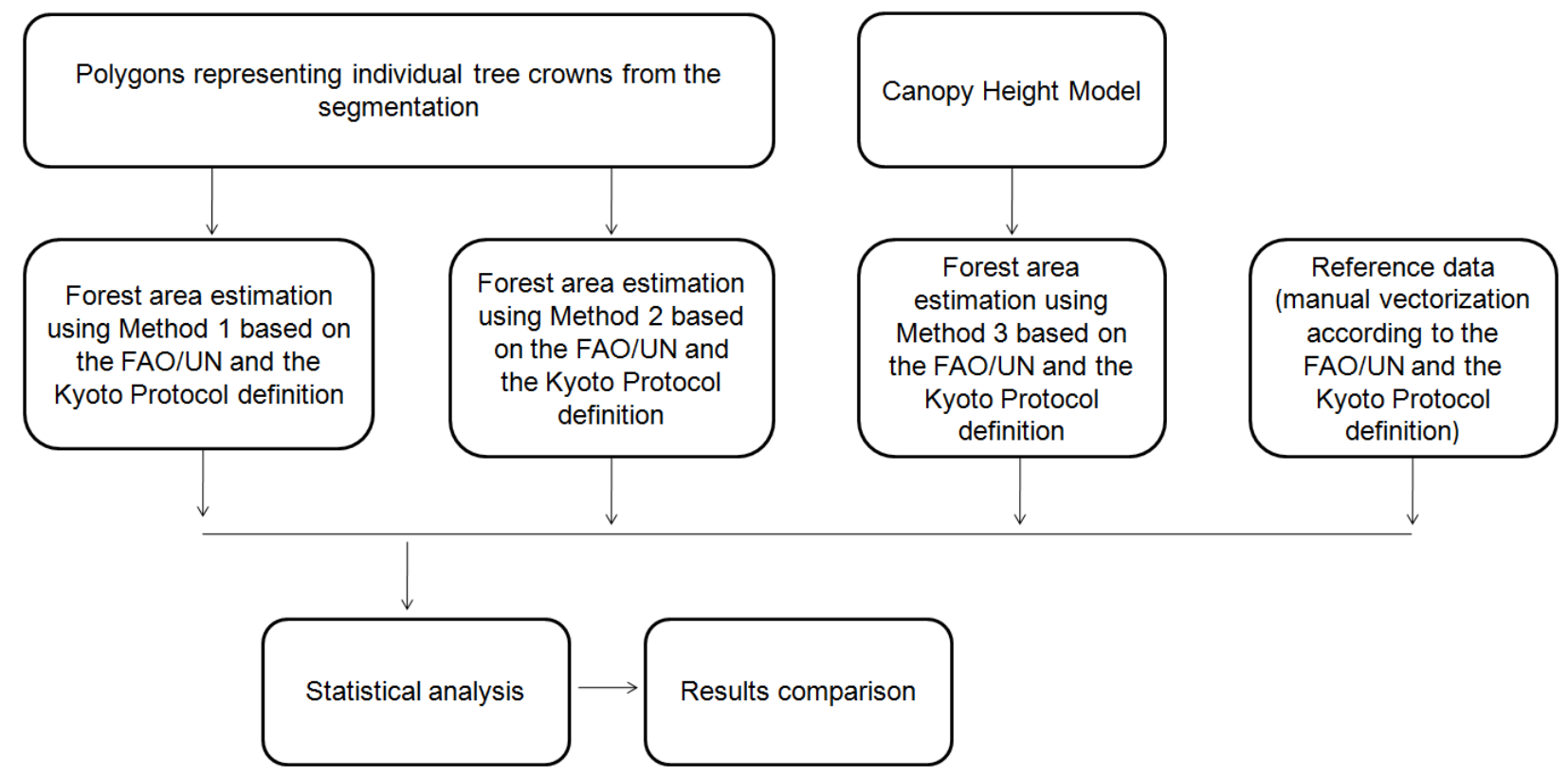

Figure 2. The scheme of the analysis.

\subsection{Methods for Determining the Canopy Coverfrom ALS Data}

For the $\mathrm{FAO} / \mathrm{UN}$ definition, percentage cover was determined using three different methods, which are described below.

The first method is based on a triangular grid such that each point representing a tree is the vertex of one of the triangles. Such a triangular grid can be created using the Delauney triangulation method. Irregular polygons created during a segmentation process were used to represent the individual trees of $5 \mathrm{~m}$ and higher. The areas for which percent cover is calculated ("Convex Hull") were created based on groups of trees (three each) defined by the vertices of the triangles, as shown below. This method was used in the analysis and abbreviated as Method 1 [50-53] (Figure 3).

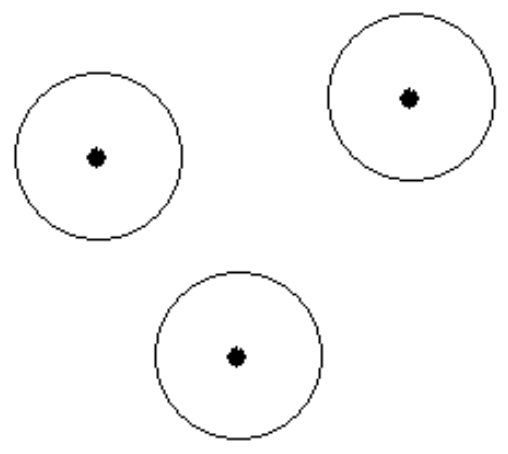

tree ositions and tree crowns

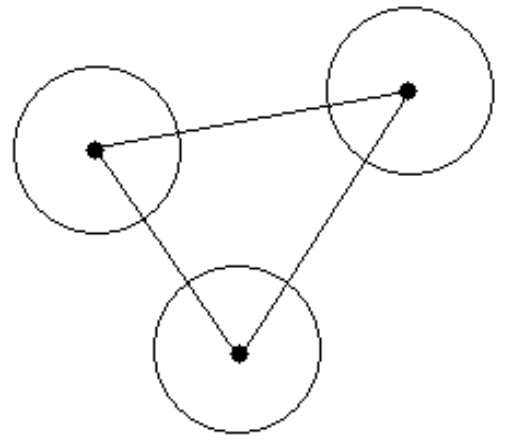

connected tree triple

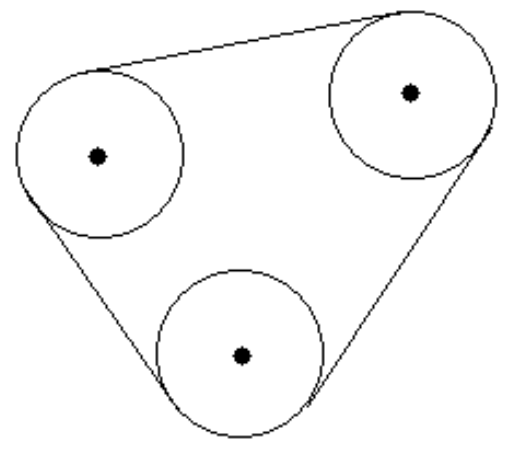

$\mathrm{CC}=$ crown area vs. "convex hull"

Figure 3. Area for which the percentage cover is calculated: Method 1 [50-53].

The second method uses only the polygons representing individual tree crowns from the segmentation [54]. This method was abbreviated as Method 2 (Figure 4). 

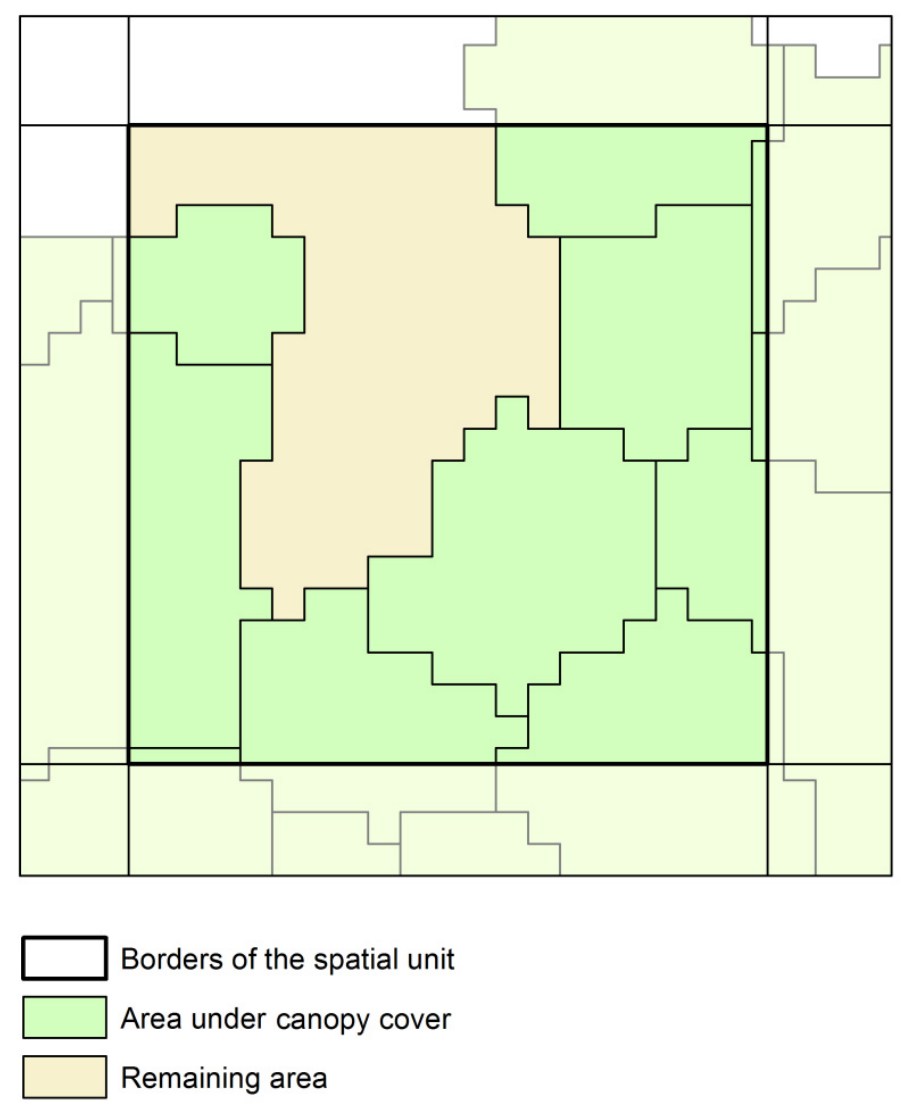

Figure 4. Area for which the percentage cover is calculated: Method 2 [54].

The third method uses only the pixels representing forest vegetation with a height of at least $5 \mathrm{~m}$ on Canopy Height Model [27-29]. This method was abbreviated as Method 3 (Figure 5).

For the Kyoto Protocol definition, the criteria were a minimum height of $2 \mathrm{~m}, 10 \%$ for percentage cover, and 0.1 ha for the area of a forest complex. For the Kyoto Protocol definition, percent cover was calculated in the same way as for the FAO/UN definition described above.

At the final stage, the results consist of 6 levels ( 3 methods times 2 definitions) representing the area covered by forest vegetation for the Milicz study area described in the "Study Area" section. The three methods were summarized in Table 4.

\subsection{The Reference Data}

The accuracy of the above methods was verified by manual vectorization performed on a selected set of 270 test plots $\left(10 \times 10 \mathrm{~m}^{2}\right)$ and 30 test plots $\left(30 \times 30 \mathrm{~m}^{2}\right)$ in the Milicz study area according to the definition formulated by FAO/UN and the Kyoto Protocol.

The centre of the test plots was selected from the circular test plots established during the field inventory. The data from the study area-tree height, canopy length and width measured in two directions-helped in vectorization based on the tree canopy height model and orthophotomap. Crown length and width were measured using a simple tape measure. Tree height was measured using the Vertex IV device (Haglof Sweden AB, Langsele, Sweden). Each test plot was classified as forest or no forest based on the height and canopy criteria.

An example of the vectorization results is shown in Figure 6. The results can be found in Table 3. 

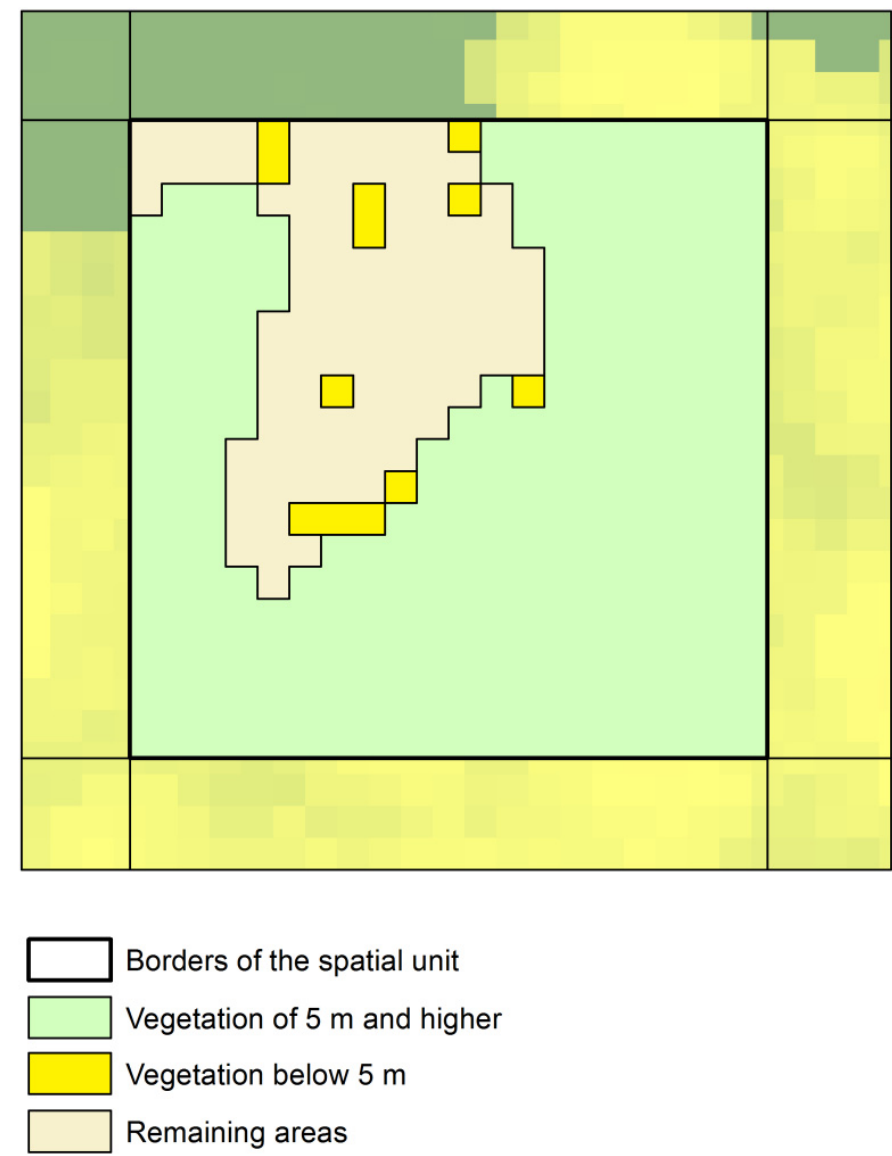

Borders of the spatial unit

Vegetation of $5 \mathrm{~m}$ and higher

Vegetation below $5 \mathrm{~m}$

Remaining areas

Figure 5. Area for which the percentage cover is calculated: Method 3 [27-29].

Table 4. The summary of the three methods.

\begin{tabular}{|c|c|c|}
\hline Method & Reference & Description \\
\hline Method 1 & $\begin{array}{c}\text { Eysn et al., 2010, 2011, } 2012 \\
\text { Sakcov and Kardos, } 2014 \\
\text { [50-53] }\end{array}$ & $\begin{array}{l}\text { The first method is based on a triangular grid } \\
\text { such that each point representing a tree is the } \\
\text { vertex of one of the triangles. Such a triangular } \\
\text { grid can be created using the Delauney } \\
\text { triangulation method. Irregular polygons } \\
\text { created during a segmentation process were } \\
\text { used to represent the individual trees of } 5 \mathrm{~m} \text { and } \\
\text { higher. The areas for which percent cover is } \\
\text { calculated ("Convex Hull”) were created based } \\
\text { on groups of trees (three each) defined by the } \\
\text { vertices of the triangles. }\end{array}$ \\
\hline Method 2 & Straub et al., 2008 [54] & $\begin{array}{l}\text { The second method uses only the polygons } \\
\text { representing individual tree crowns from the } \\
\text { segmentation }\end{array}$ \\
\hline Method 3 & $\begin{array}{l}\text { Wang et al., 2007, 2007, } 2008 \\
\text { [27-29] }\end{array}$ & $\begin{array}{l}\text { The third method uses only the pixels } \\
\text { representing forest vegetation with a height of at } \\
\text { least } 5 \mathrm{~m} \text { on the Canopy Height Model }\end{array}$ \\
\hline
\end{tabular}



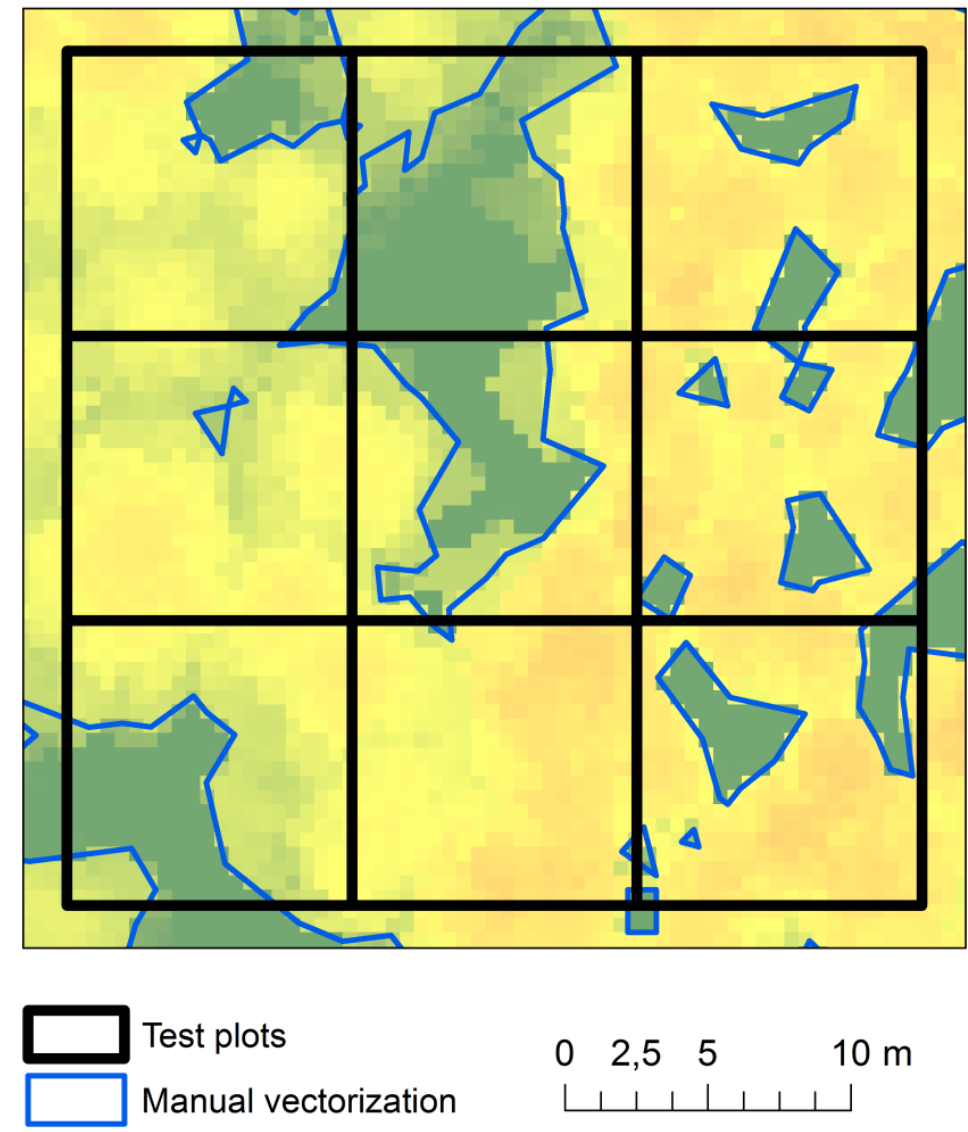

Test plots

Manual vectorization

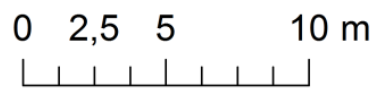

$46 \mathrm{~m}$

$0 \mathrm{~m}$

Figure 6. The example of the vectorization results.

\subsection{Statistical Analysis}

The accuracy of the above methods on the selected group of 270 test plots $\left(10 \times 10 \mathrm{~m}^{2}\right)$ and 30 test plots $\left(30 \times 30 \mathrm{~m}^{2}\right)$ in the Milicz study area according to the definition formulated by FAO/UN and Kyoto Protocol was evaluated using Mean Bias Error (MBE), Root Mean Square Error (RMSE\%) and Mean Absolute Percentage Error (MAE\%) according to the following formulas:

$$
\begin{gathered}
M B E=\frac{\sum_{i=1}^{n}\left(y_{i}-\hat{y}_{i}\right)}{n} \\
R M S E \%=\frac{R M S E}{\bar{y}} * 100
\end{gathered}
$$

where

$$
\begin{gathered}
R M S E=\sqrt{\frac{\sum_{i=1}^{n}\left(y_{i}-\hat{y}_{i}\right)^{2}}{n}} \\
M A E \%=\frac{M A E}{\bar{y}} * 100
\end{gathered}
$$

where

$$
M A E=\frac{1}{n} \sum_{i=1}^{n}\left|y_{i}-\hat{y}_{i}\right|
$$

where

$n$ is the number of observations $\left(270\right.$ test plots $\left(10 \times 10 \mathrm{~m}^{2}\right)$ and 30 test plots $\left.\left(30 \times 30 \mathrm{~m}^{2}\right)\right)$, 
$y_{i}$ is the reference area of forest vegetation, $\hat{y}_{i}$ is the estimated area of forest vegetation by Method 1, 2 or 3 .

$\bar{y}$ is the mean of the observed area of forest vegetation.

The estimated area of forest vegetation by Method 1, 2 or 3 and reference data were also compared using a Pearson correlation coefficient (R).

\subsection{Limitations of the Study}

The study refers to the estimation of the areas of forest vegetation according to the international definitions (height, canopy, area of forest complex). It does not take into account land use and the determination of areas that constitute forests or non-forests, regardless of forest vegetation. The study is based on the level of polygons representing the tree canopy from the segmentation of objects, manual vectorization of the tree canopy model, statistical tests, etc., which have their own accuracy and limitations. Natural forest characteristics may also influence the results. All three methods can be performed using a tree canopy height model and appropriate software, e.g., ArcGIS or QGIS.

\subsection{Assumptions and Boundary Conditions}

Based on the specificity of the methods tested, Method 2 [54] was assumed to be closest to the analysis results using the reference data. Method 1 [50-53] accounts for the area between the crowns of individual trees that resulted from triangulation, which may result in an overestimation of the area with forest vegetation. Method 3 [27-29], on the other hand, does not consider the area of tree crowns below the required threshold, which may lead to an underestimation of the area with forest vegetation.

To perform the analysis, a model of tree canopy height with a maximum size of $1 \mathrm{~m}$ pixel generated from a dense point cloud is required. In addition, the detection of individual trees needs to be mapped. Moreover, tools for data processing and spatial analysis (e.g., QGIS or ArcGIS) are required.

\section{Results}

Of the 270 test plots, 181 were a forest according to the FAO/UN definition and 189 according to the UNFCCC definition. Out of 30 test plots, 23 were a forest as per FAO/UN definition and 23 as per UNFCCC definition. The accuracy of the above methods was verified by manual vectorization performed on a selected set of 270 test plots $\left(10 \times 10 \mathrm{~m}^{2}\right)$ and 30 test plots $\left(30 \times 30 \mathrm{~m}^{2}\right)$ in the Milicz study area according to the definition formulated by FAO/UN and Kyoto Protocol. The results are presented in Table 5.

Classification accuracy varied between the Methods; independently of scale $(10 \mathrm{~m}$ or $30 \mathrm{~m}$ ) and the definition (FAO/UN or Kyoto), the highest levels of accuracies were obtained for classification by Method 2 and the values of overall accuracy and Kappa were very high $(\mathrm{OA}>97 \%$, Kappa $>0.94)$. It is worth noticing that Method 3 resulted in the same excellent accuracies in the case of 30 test plots per UNFCCC definition. Method 1 turned out to be the worst option and resulted in $83 \%<\mathrm{OA}<93 \%$ and $0.38<\kappa<0.79$.

The area of forest vegetation accuracies are shown in Table 5. On the basis of these results, we can state that among analysed methods, Method 2 was the most accurate one in the case of both definitions, with the values of RMSE\% and $\mathrm{MAE} \%$ less than $3 \%$ independently of the grid size $(200 \mathrm{~m}$ or $30 \mathrm{~m})$. Strong linear correlations between estimated Method 2 values of the area of forest vegetation and reference data were observed $\left(\mathrm{R}^{2} \approx 0.99\right.$, Figures A1-A12). Additionally, Method 2 resulted in the lowest MBE values (Figures A1-A12). 
Table 5. The number of test plots $\left(10 \times 10 \mathrm{~m}^{2}\right.$ and $\left.30 \times 30 \mathrm{~m}^{2}\right)$ with the forest vegetation of $\geq 10 \%$ according to particular methods and definitions.

\begin{tabular}{|c|c|c|c|c|}
\hline Definition & Method 1 & Method 2 & Method 3 & Reference \\
\hline \multicolumn{5}{|c|}{270 test plots $\mathrm{FAO} / \mathrm{UN}$} \\
\hline Forest plots & 214 & 187 & 167 & 181 \\
\hline Overall accuracy & $87.8 \%$ & $97.8 \%$ & $94.8 \%$ & $n / a$ \\
\hline Kappa & 0.69 & 0.95 & 0.89 & $n / \mathrm{a}$ \\
\hline Commission & $18.2 \%$ & $3.3 \%$ & $n / \mathrm{a}$ & $n / \mathrm{a}$ \\
\hline Omission & $n / a$ & $n / \mathrm{a}$ & $7.7 \%$ & $n / \mathrm{a}$ \\
\hline \multicolumn{5}{|c|}{270 test plots UNFCCC } \\
\hline Forest plots & 232 & 196 & 198 & 194 \\
\hline Overall accuracy & $84 \%$ & $97.4 \%$ & $96.7 \%$ & $n / a$ \\
\hline Kappa & 0.55 & 0.94 & 0.92 & $n / a$ \\
\hline Commission & $22.8 \%$ & $3.7 \%$ & $4.8 \%$ & $n / \mathrm{a}$ \\
\hline Omission & $n / \mathrm{a}$ & $n / \mathrm{a}$ & $n / \mathrm{a}$ & $n / \mathrm{a}$ \\
\hline \multicolumn{5}{|c|}{30 test plots $\mathrm{FAO} / \mathrm{UN}$} \\
\hline Forest plots & 25 & 23 & 21 & 23 \\
\hline Overall accuracy & $93.3 \%$ & $100 \%$ & $93.3 \%$ & $n / \mathrm{a}$ \\
\hline Kappa & 0.79 & 1 & 0.83 & $n / a$ \\
\hline Commission & $8.7 \%$ & $0 \%$ & $n / \mathrm{a}$ & $n / \mathrm{a}$ \\
\hline Omission & $n / \mathrm{a}$ & $0 \%$ & $8.7 \%$ & $n / \mathrm{a}$ \\
\hline \multicolumn{5}{|c|}{30 plots UNFCCC } \\
\hline Forest plots & 28 & 23 & 23 & 23 \\
\hline Overall accuracy & $83.3 \%$ & $100 \%$ & $100 \%$ & $n / \mathrm{a}$ \\
\hline Kappa & 0.38 & 1 & 1 & $n / a$ \\
\hline Commission & $21.7 \%$ & $0 \%$ & $0 \%$ & $n / \mathrm{a}$ \\
\hline Omission & $n / \mathrm{a}$ & $0 \%$ & $0 \%$ & $n / \mathrm{a}$ \\
\hline
\end{tabular}

Inconclusive results were achieved for Method 3. Method 3 resulted in moderate accuracies, with an RMSE $\%$ and MAE $\%$ less than 20\% according to UNFCCC protocol and strong linear correlation $\left(\left(\mathrm{R}^{2}>0.96\right.\right.$, Figures A1-A12). Method 3 worked the worst in the case of the second definition $\left(51 \% \leq \mathrm{RMSE} \% \leq 56 \%, \mathrm{MAE} \% \approx 27 \%, 0.60 \leq \mathrm{R}^{2} \leq 0.64\right)$. The values of the measurements underestimate the forest area in case of the FAO definition and they overestimate the forest area due to the Kyoto definition.

Conversely, Method 1 provided the largest errors (RMSE\% from $68.7 \%$ to $97.8 \%$ and MAE \% from $57.8 \%$ to $70.3 \%$ ). The values of Pearson correlation coefficient for that method varied from $73.5 \%$ to $83.7 \%$. High positive values of the MBE means that measurements by Method 1 overestimate the area of forest vegetation (Table 6, Figures A1-A12). 
Table 6. Results comparison for the methods according to the FAO/UN and the Kyoto Protocol definitions.

\begin{tabular}{|c|c|c|c|}
\hline Definition & Method 1 & Method 2 & Method 3 \\
\hline \multicolumn{4}{|c|}{270 test plots FAO/UN } \\
\hline MBE & 123.87 & -0.76 & -33.90 \\
\hline RMSE\% & $97.8 \%$ & $3.0 \%$ & $55.8 \%$ \\
\hline $\mathrm{MAE} \%$ & $70.3 \%$ & $2.1 \%$ & $27.3 \%$ \\
\hline $\mathrm{R}^{2}$ & 0.50 & 0.998 & 0.64 \\
\hline \multicolumn{4}{|c|}{270 test plots UNFCCC } \\
\hline MBE & 115.31 & -1.10 & 20.34 \\
\hline RMSE\% & $79.3 \%$ & $3.0 \%$ & $18.4 \%$ \\
\hline MAE $\%$ & $57.8 \%$ & $2.1 \%$ & $10.4 \%$ \\
\hline $\mathrm{R}^{2}$ & 0.54 & 0.99 & 0.96 \\
\hline \multicolumn{4}{|c|}{30 test plots $\mathrm{FAO} / \mathrm{UN}$} \\
\hline MBE & 1114.83 & -6.80 & -305.07 \\
\hline RMSE\% & $86.2 \%$ & $1.1 \%$ & $51.4 \%$ \\
\hline MAE $\%$ & $70.3 \%$ & $0.9 \%$ & $26.6 \%$ \\
\hline $\mathrm{R}^{2}$ & 0.65 & 0.99 & 0.60 \\
\hline \multicolumn{4}{|c|}{30 test plots UNFCCC } \\
\hline MBE & 1037.83 & -9.87 & 183.03 \\
\hline RMSE\% & $68.7 \%$ & $1.7 \%$ & $15.4 \%$ \\
\hline MAE\% & $57.8 \%$ & $1.3 \%$ & $10.2 \%$ \\
\hline$R^{2}$ & 0.70 & 0.99 & 0.97 \\
\hline
\end{tabular}

\section{Discussion}

The study refers to the estimation of areas of forest vegetation according to the international definitions (height, canopy cover, area of forest complex). It does not take into account land use and the determination of area representing forests or non-forests regardless of forest vegetation. The study is based on the layer of polygons representing tree canopy from object segmentation, Canopy Height Model manual vectorization, statistical tests, etc., which have their own accuracy and limitations. Natural forest characteristics may also influence the results. All three methods may be performed using a Canopy Height Model and the suitable software, e.g., ArcGIS or QGIS.

Classification accuracy varied between the methods independently of scale and the definition, the highest levels of accuracies were obtained for classification by Method 2, values of overall accuracy and Kappa were very high (OA > 97\%, Kappa > 0.94). Method 3 resulted in the same excellent accuracies in the case of 30 test plots per UNFCCC definition. Method 1 turned out to be the worst option.

There are many approaches to forest area delineation based on remote sensing data. In this paper, we focus on the use of airborne laser scanning data and the estimation of three variables that determine the presence of forest vegetation in the international forest definitions: elevation, crown projection area, and forest complex area, which have not been fully addressed in previous work. In the work, we use three methods for calculating tree canopy cover proposed by: Eysn et al. and Sackov and Kardos [50-53] (Method 1); Straub et al. [54] (Method 2) and Wang et al. [27-29] (Method 3). However, no publication was found comparing the methods used to calculate the degree of canopy cover with each other and with the reference data. Method 2 was the most accurate for both definitions, with values of RMSE\% and MAE \% of less than 3\% regardless of grid size (200 $\mathrm{m}$ or $30 \mathrm{~m}$ ) and a 
strong linear correlation between the results and the reference data of $\mathrm{R} 2 \approx 0.99$. Method 3 resulted in moderate accuracies, with an RMSE \% and MAE\% of less than $20 \%$ according to the UNFCCC protocol and the linear correlation of $\mathrm{R}^{2}>0.96$. Method 1 performed worst in the case of the UNFCCC definition. The accuracy obtained in our study (83.3-100\%) is comparable to the accuracy of Haapanen [20] - 80-91\%, Straub [54]-97.7\%, Sackov and Kardos [53]-93\%, Pekkarinen [30]-80-90\%, Eysn [50-52]-96-98.4\%, Pujar [36]-76-79\%, Kolecka [34]-95\% and Naesset [26] -random errors of $1-4.6 \%$.

In the case of the FAO/UN definition, Methods 1 and 2 overestimate forest area and Method 3 underestimates it. In the case of the Kyoto Protocol definition, all definitions overestimate the forest area compared to the reference data. This is true for the accuracy analysis of 270 sample plots $\left(100 \mathrm{~m}^{2}\right.$ area). For the analysis of 30 sample plots $\left(900 \mathrm{~m}^{2}\right.$ area), Method 1 overestimates the forest area, and Methods 2 and 3 reach the accuracy limit of $100 \%$.

It is worth noting that the minimum area of forest land according to FAO/UN and UNFCCC definitions is 0.1 ha, which is slightly more than the largest sample plots in terms of the area used in our study. It is reasonable to assume that the smaller the scale of the analysis (i.e., the larger the area analyzed), the smaller the differences between the results, which is particularly important when reporting a country-wide forest area.

Aerial and satellite imagery, as well as data from airborne laser scanning [38-47], allows for segmentation and thus the creation of polygons representing the crowns of individual trees with a given projected area. It is possible to use multiple aerial images and to obtain the height information using the stereo matching method [59], which creates a three-dimensional data space from the two-dimensional images. Unfortunately, this method is susceptible to illumination conditions and provides less accurate results when there are many shadows on the input images. Airborne laser scanner data is resistant to this problem.

For accuracy analysis, a reference in the form of manual vectoring of the areas with forest vegetation on the sample plots, canopy height model and orthophotomap was used and was supported by the individual tree height and canopy data (measured in 4 directions) from the sample plots. Such distance data used to collect reference information can be considered to be a very good and accurate data source. In addition, the reference data were also performed manually by Eysn [50-52], Sackov and Kardos [53], Wang [27-29], Straub [54]. Kolecka [34] and Pekkarinen [30], who performed the accuracy analysis based on the test points or polygons. Pujar [36] performed only the visual analysis. Finally, we assume that the reference data we used is accurate enough. We can assume that the best option for reference data would be to measure all trees on the sample plots, including height and crown size, measured in 8 directions. This would of course require an incomparably larger amount of work. Nevertheless, we are confident that the reference data used in this study are reliable and often better than those used in other studies of this type.

The high cost of analyses over increasingly large areas should also be noted. Since the difference between the results obtained becomes smaller as the area size increases, the method with the lowest processing costs and times should be chosen. The least demanding method in this respect is Method 3 and should be considered as an alternative when analyzing large areas, as it has a similar accuracy to Method 2.

In this paper, for the first time, methods for determining the area for which canopy cover is calculated (using data from (ALS) are compared and the differences between them in terms of accuracy (the agreement between the results and the reference data) and the complexity of the process (time and effort required to perform the analysis) are discussed. The area with forest vegetation is a starting point for the assessment of forest area according to the international definitions, taking into account land use and its future evolution, even without the current forest vegetation. This in turn is important in the context of reporting, estimating carbon stocks and biodiversity to mitigate the effects of climate change.

International organizations such as the FAO/UN and the UNFCCC require signatory countries to maintain and increase the area of forests and other areas with forest vegetation. 
The methodology proposed in this article can help monitor afforestation with a similar and objective methodology. Forests play an important role in the accumulation of carbon stocks, the release of which into the atmosphere would increase the negative effects of climate change. In addition, forests are important for biodiversity, provide environmental services and influence quality of life and health $[60,61]$. Therefore, by using good forest monitoring methods, we are not only improving this tool, but also solving many other problems that contribute to the management and protection of forests. Above all, however, we are helping to create a forestry policy based on a consistent, objective and uniform methodology.

\section{Conclusions}

This paper is the first to compare three consistent, objective, and uniform methods for defining the area for which canopy cover is calculated (using ALS data) to define forest area. Two forest definitions were used: UNFCCC and Kyoto, and analyses were conducted at different spatial scales. Differences between the methods used were discussed in terms of accuracy (agreement of results with reference data) and complexity of the process (time and effort required to perform the analysis).

Of the methods tested, Method 2 proved to be the most accurate for both definitions (UNFCCC and Kyoto). Strong linear correlations were found between the values of the forest vegetation area estimated by Method 2 and the reference data. Method 1 was found to be the worst option. Method 1 contained the largest errors and overestimated the forest vegetation area.

The complexity of the methods was related to the need to invest more time and equipment in their implementation. Since the difference between the results of the different methods becomes smaller as the size of the analyzed area increases, the method with the least effort for its implementation should be chosen. The least demanding method in this respect is Method 3, which should be considered as an alternative for large-scale analyses due to its similar accuracy to Method 2.

The results obtained are important for the management and protection of forest areas. Accurate and efficient estimation of forest area is important for reporting, carbon stock estimation, forest conservation and management, afforestation monitoring and biodiversity monitoring for climate change mitigation.

Author Contributions: T.H. performed the literature search, conceptual planning, analysis, writing the text and editing. A.K. helped with the statistical analyses, reviewed the text and edited it. K.S. carried out the conceptual plan, provided data and funding for the study, reviewed and edited the text. All authors have read and agreed to the published version of the manuscript.

Funding: The analyses performed in this manuscript were funded as part of a PhD project entitled "Possibility of using data from airborne laser scanning to classify forest areas in the context of different forest definitions", carried out in the Forest Research Institute during 2017-2020. Polygon layers representing the crowns of individual trees (of a given area and height), Canopy Height Model and orthophoto were used for the analyses and were created for the project entitled "Remote SensingBased Assessment of Woody Biomass and Carbon Storage in Forests". This project was financially supported by the National Centre for Research and Development (Poland) under the BIOSTRATEG program (contract number: BIOSTRATEG1/267755/4/NCBR/2015).

Institutional Review Board Statement: Not applicable.

Informed Consent Statement: Not applicable.

Data Availability Statement: Data are the property of the Forest Research Institute.

Conflicts of Interest: The authors declare no conflict of interest. 


\section{Appendix A}

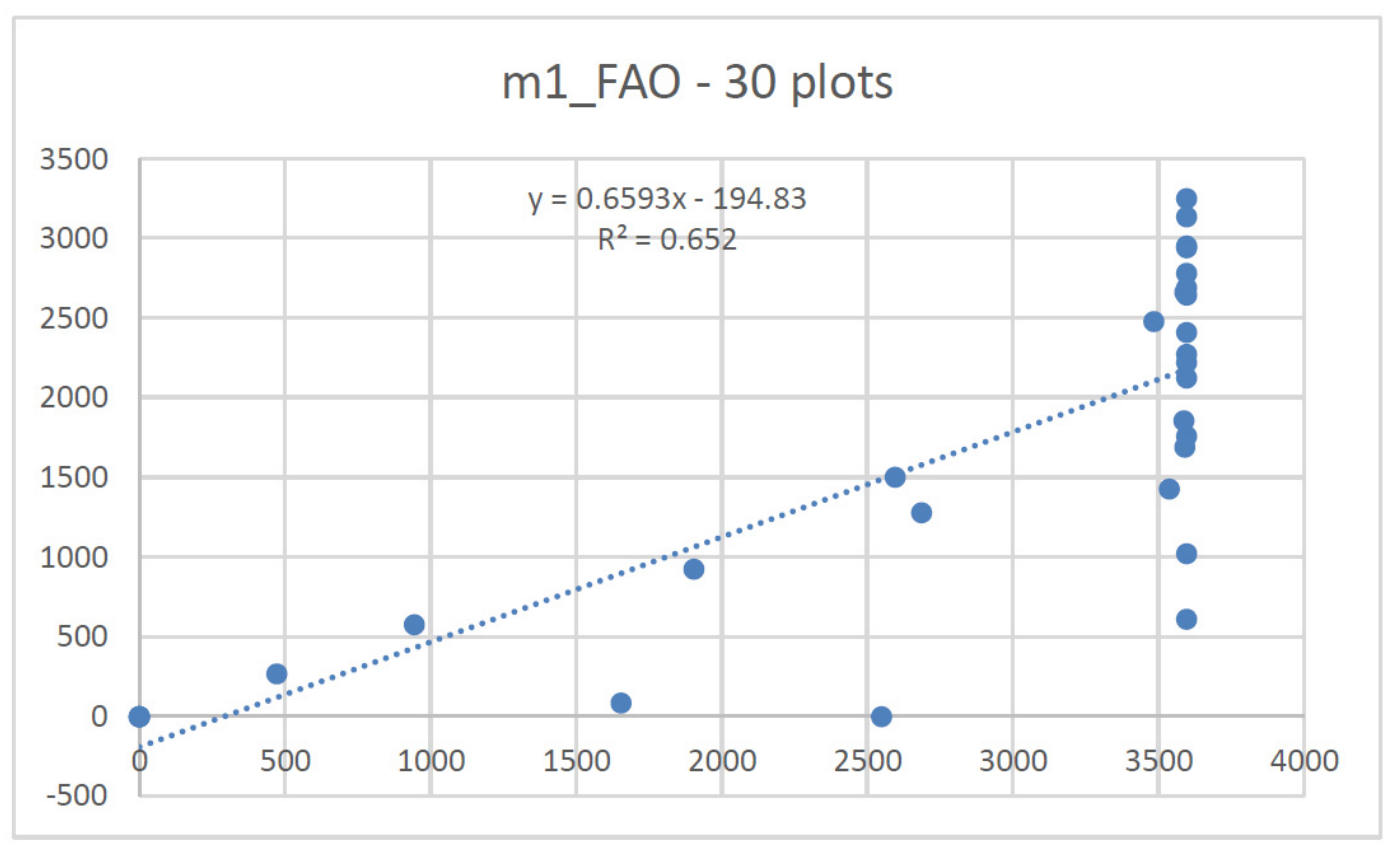

Figure A1. The reference area compared to the estimated forest area according to Method 1 for test plots $\left(30 \times 30 \mathrm{~m}^{2}\right)$ as defined by $\mathrm{FAO} / \mathrm{UN}$.

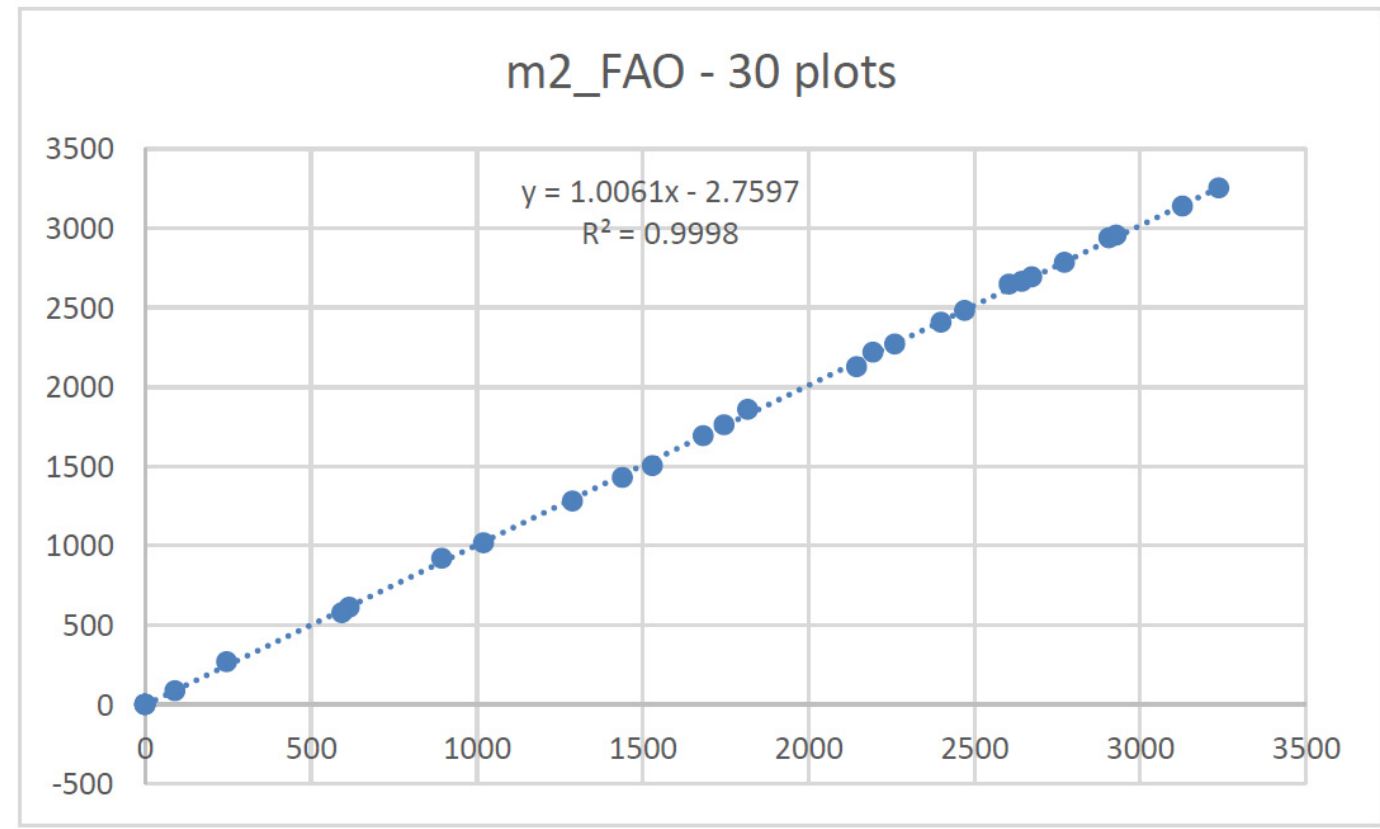

Figure A2. The reference area compared to the estimated forest area according to Method 2 for test plots $\left(30 \times 30 \mathrm{~m}^{2}\right)$ as defined by FAO/UN. 


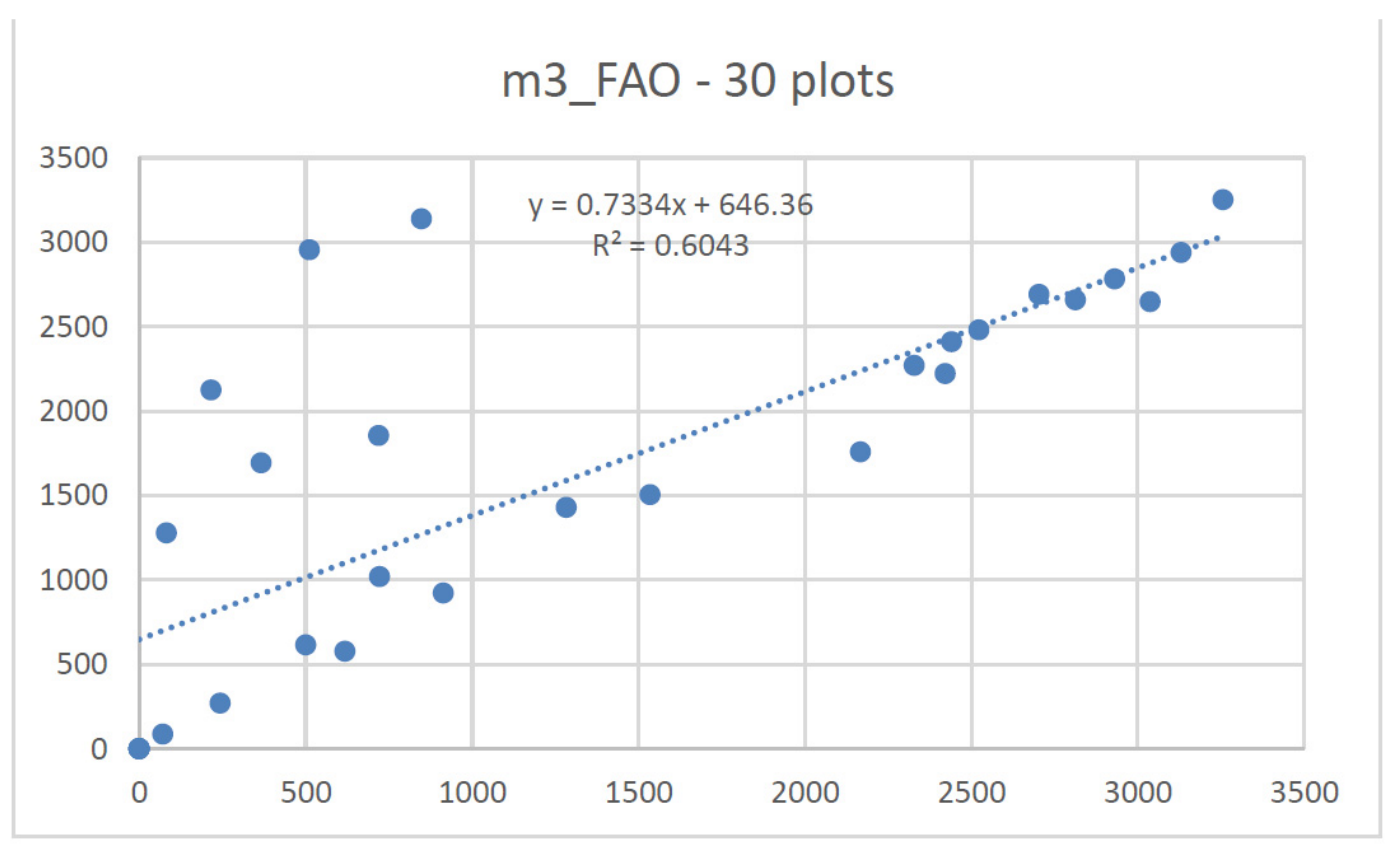

Figure A3. Reference area compared to estimated forest area by Method 3 for test plots $\left(30 \times 30 \mathrm{~m}^{2}\right)$ according to FAO/UN definition.

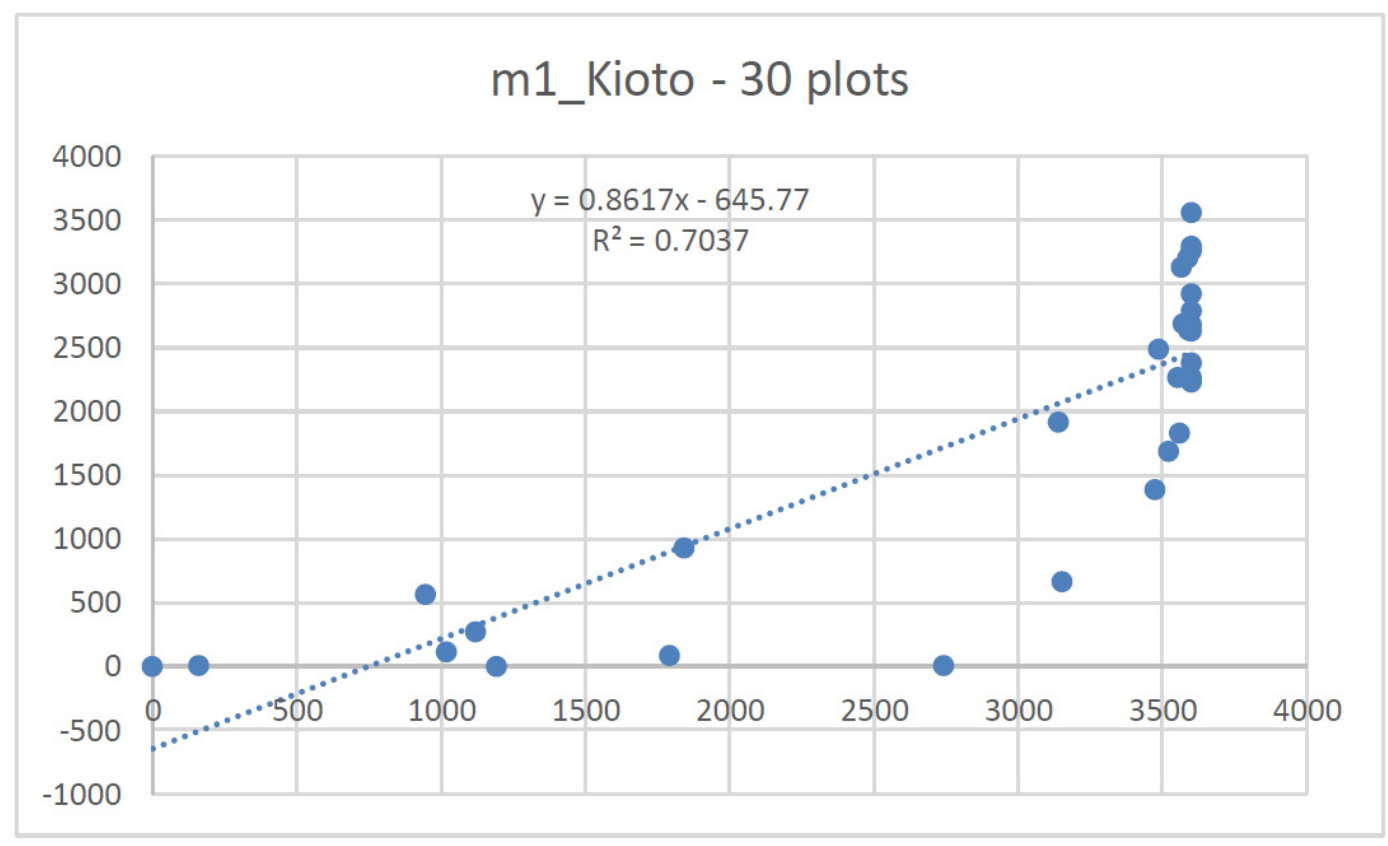

Figure A4. Reference area compared to estimated forest area by Method 1 for test plots $\left(30 \times 30 \mathrm{~m}^{2}\right)$ as defined by the UNFCCC. 


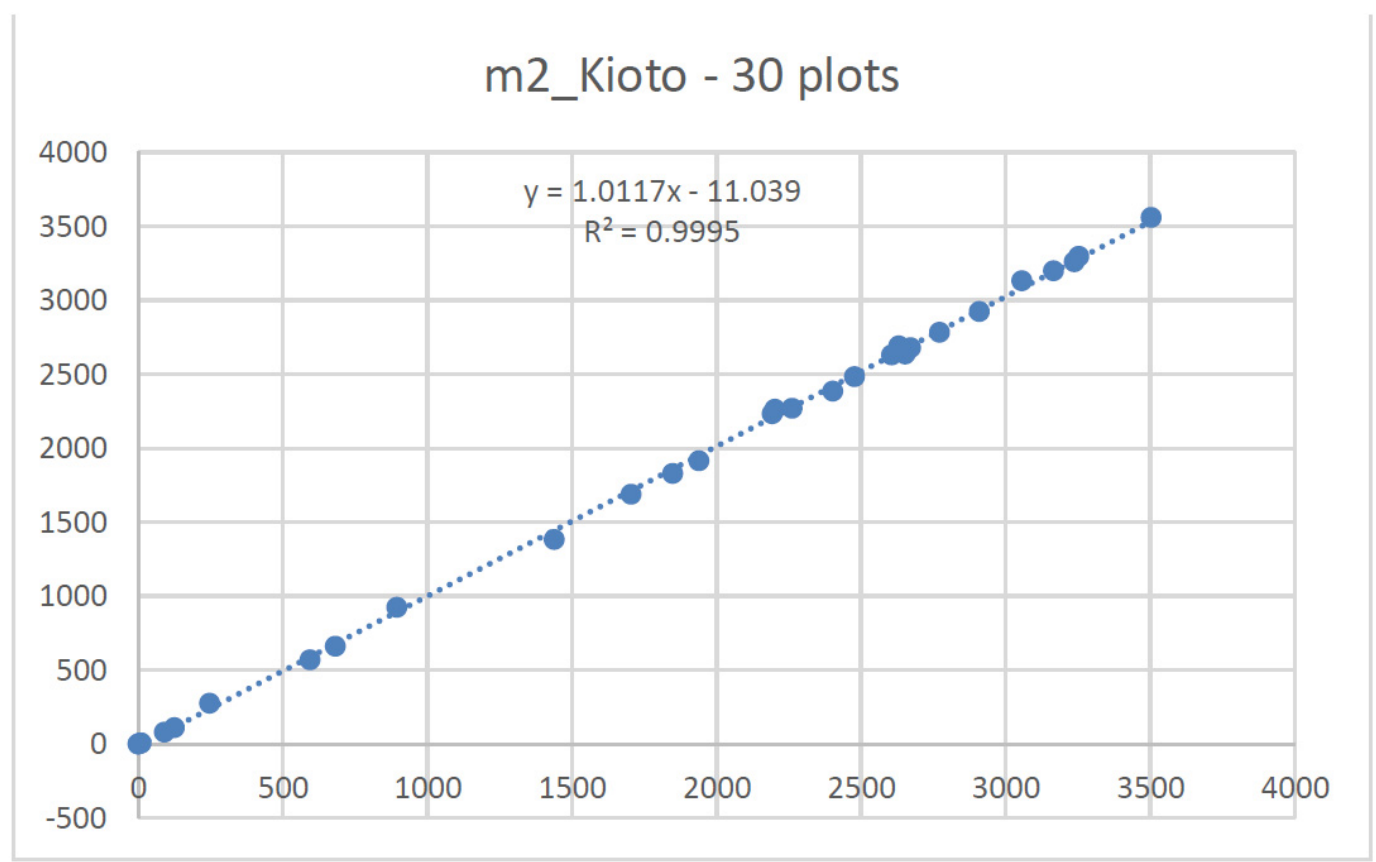

Figure A5. The reference area compared to the estimated forest area using Method 2 for test plots $\left(30 \times 30 \mathrm{~m}^{2}\right)$ as defined by the UNFCCC.

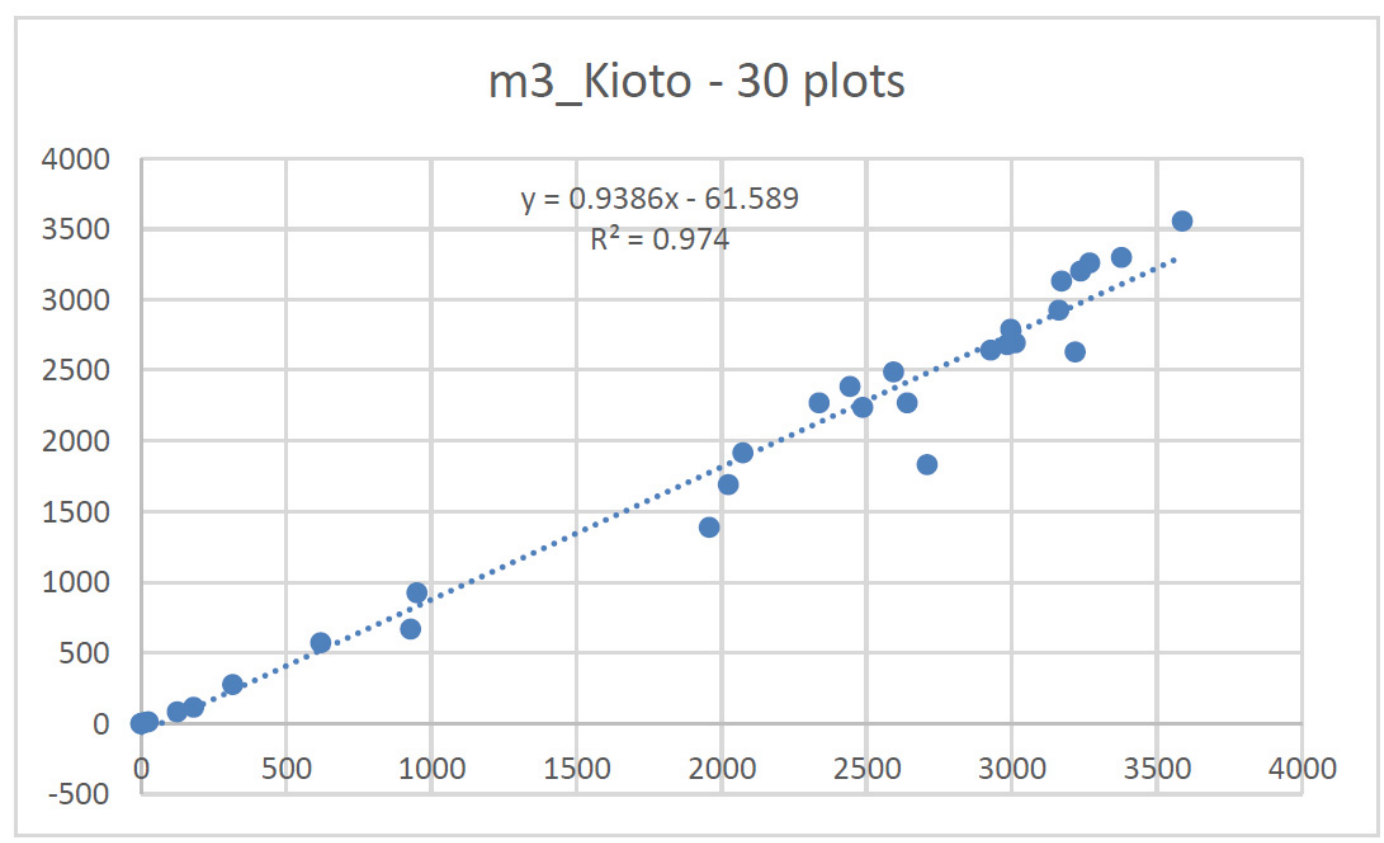

Figure A6. The reference area compared to the estimated forest area by Method 3 for test plots $\left(30 \times 30 \mathrm{~m}^{2}\right)$ according to the UNFCCC definition. 


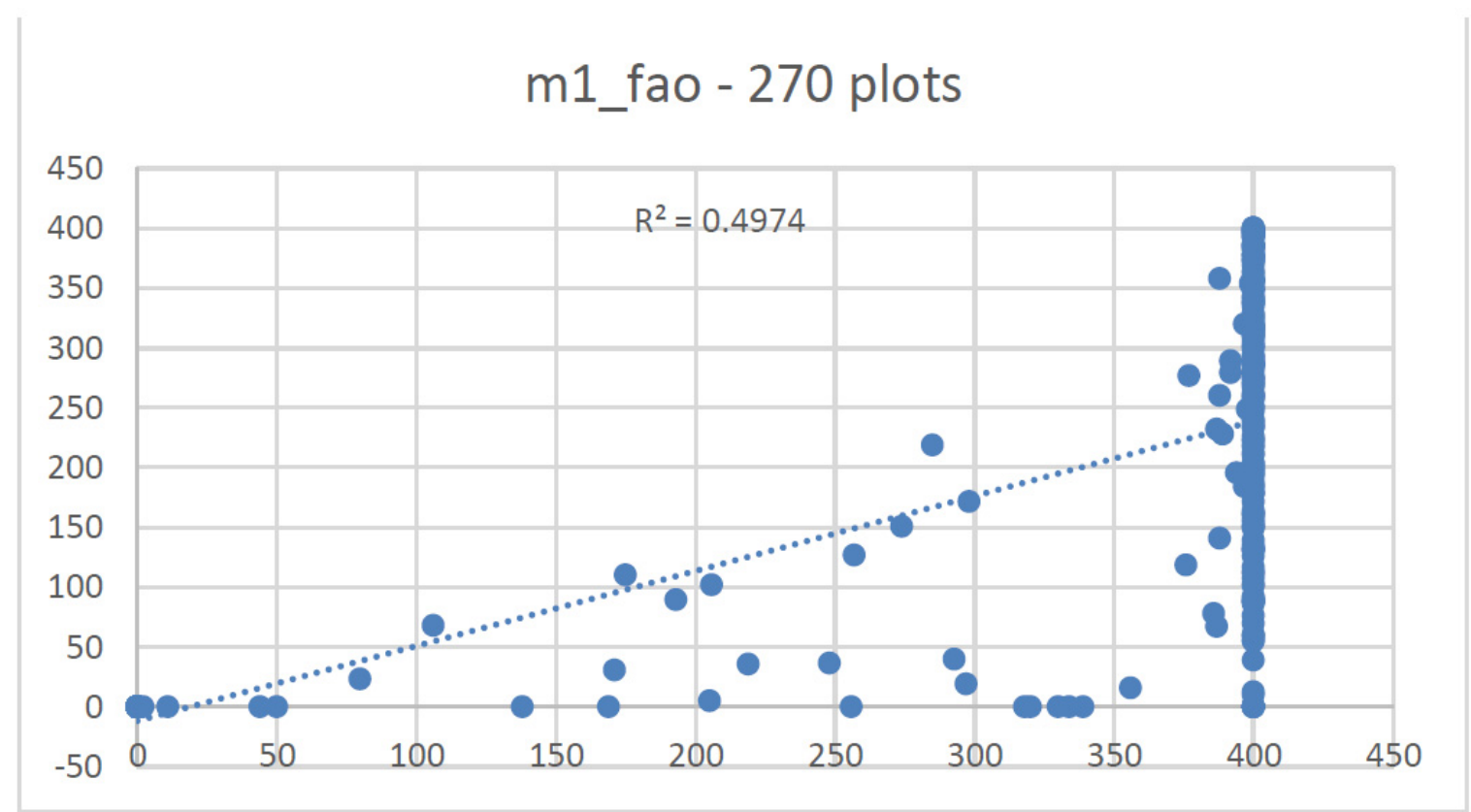

Figure A7. Reference area compared to estimated forest area by Method 1 for test plots $\left(10 \times 10 \mathrm{~m}^{2}\right)$ according to FAO/UN definition.

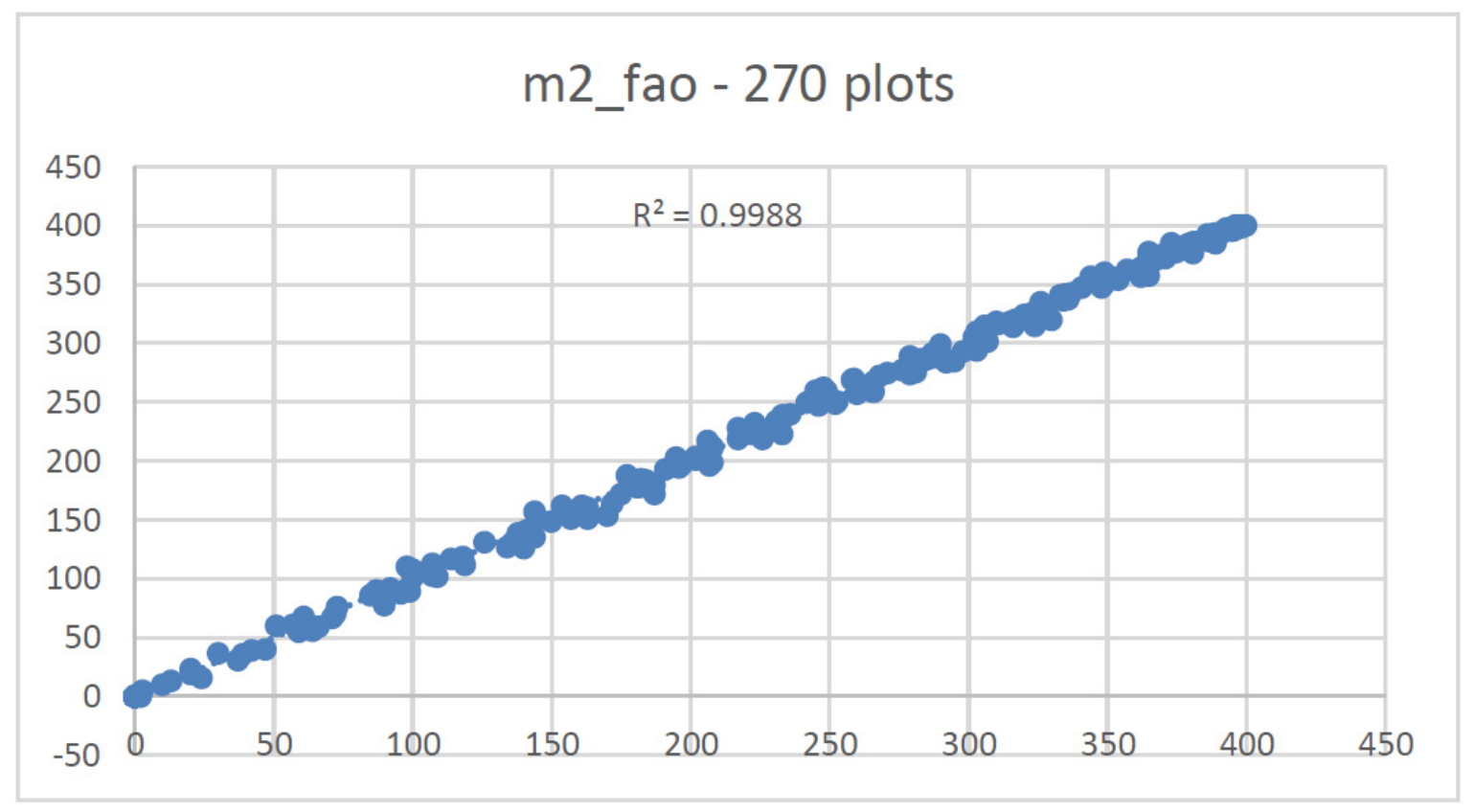

Figure A8. The reference area compared to the estimated forest area according to Method 2 for test plots $\left(10 \times 10 \mathrm{~m}^{2}\right)$ as defined by FAO/UN. 


\section{m3_fao - 270 plots}

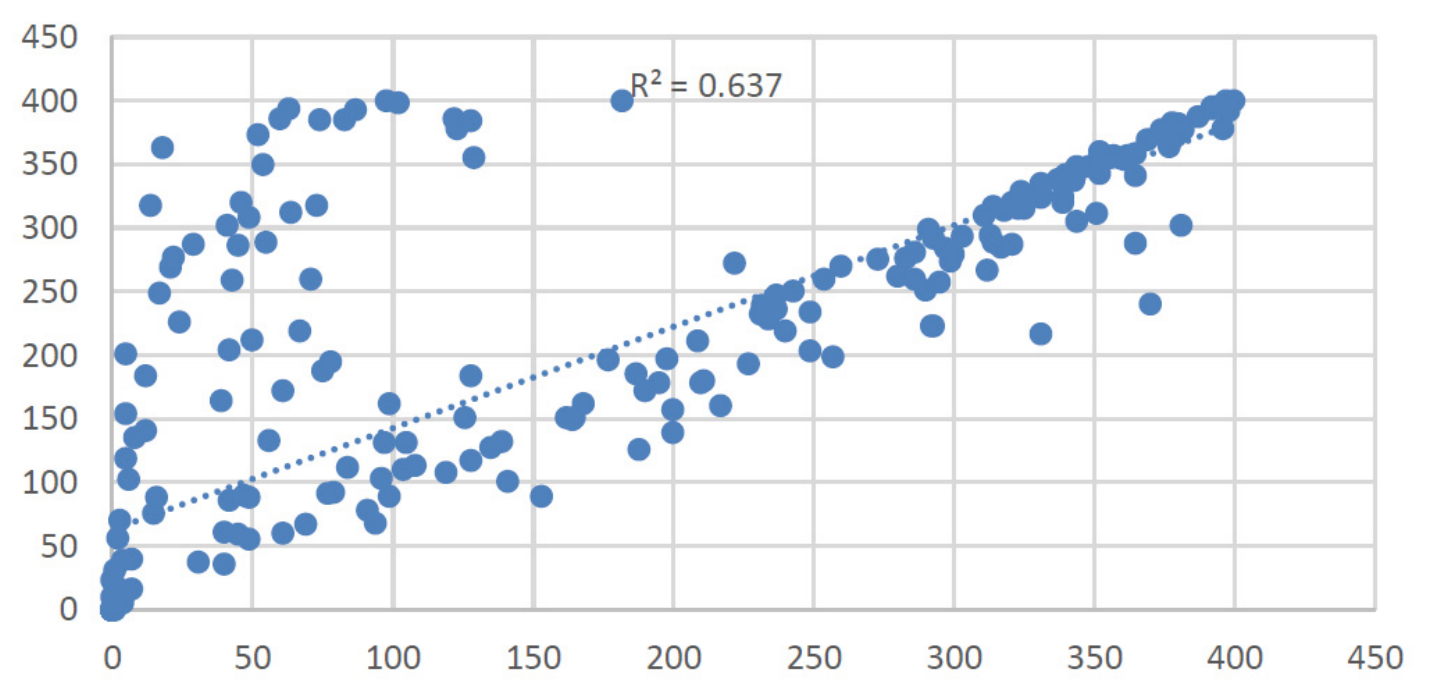

Figure A9. Reference area compared to estimated forest area by Method 3 for test plots $\left(10 \times 10 \mathrm{~m}^{2}\right)$ according to FAO/UN definition.

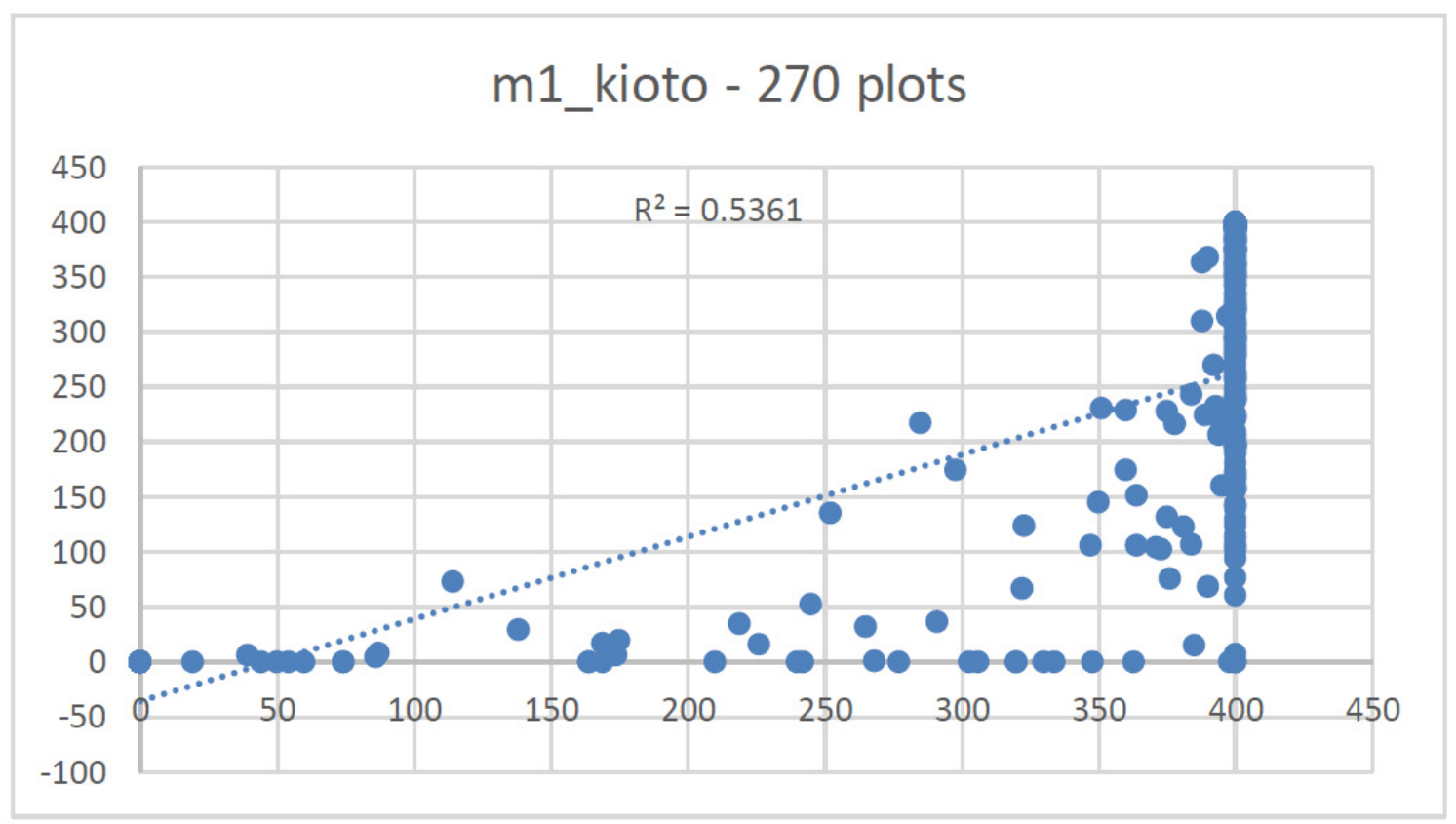

Figure A10. Reference area compared to estimated forest area by Method 1 for test plots $\left(10 \times 10 \mathrm{~m}^{2}\right)$ as defined by the UNFCCC. 


\section{m2_kioto - 270 plots}

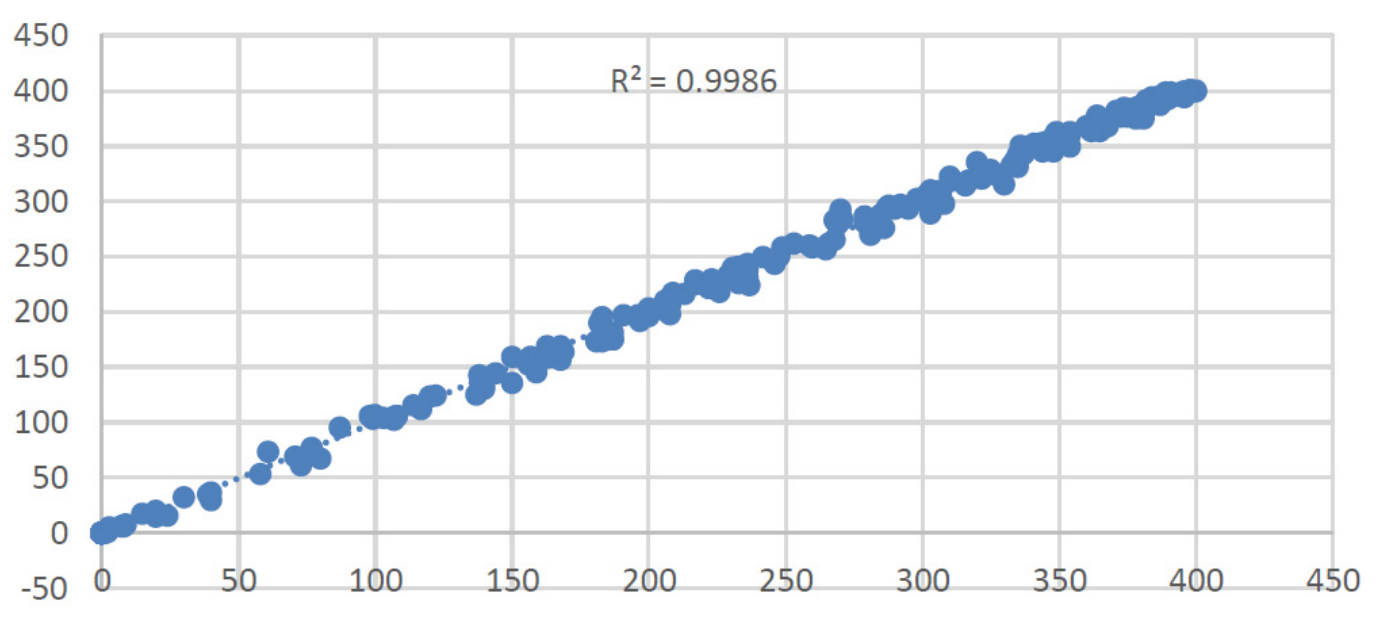

Figure A11. Reference area compared to estimated forest area by Method 1 for test plots $\left(10 \times 10 \mathrm{~m}^{2}\right)$ as defined by the UNFCCC.

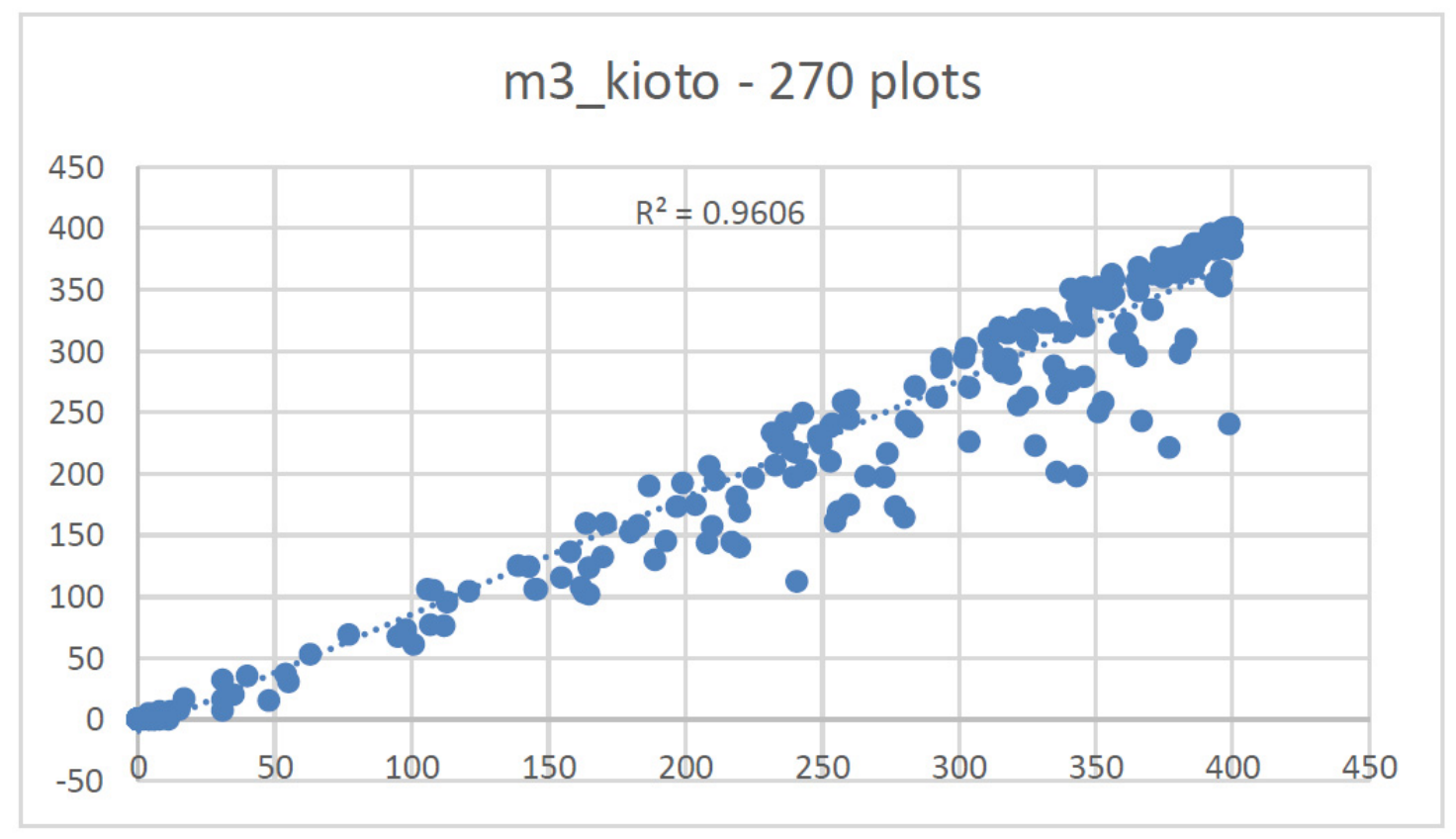

Figure A12. Reference area compared to estimated forest area by Method 1 for test plots $\left(10 \times 10 \mathrm{~m}^{2}\right)$ as defined by the UNFCCC.

\section{References}

1. Putz, F.E.; Redford, K. The Importance of Defining 'Forest': Tropical Forest Degradation, Deforestation, Long-Term Phase Shifts, and Further Transitions. Biotropica 2009, 42, 10-20. [CrossRef]

2. Traub, B.; Kohl, M.; Paivinen, R.; Kugler, O. Effects of different definitions on forest area estimation in national forest inventories in Europe. In Integrated Tools for Natural Resources Inventories in the 21st Century; General Technical Report NC-212; Hansen, M., Burk, T., Eds.; General Technical Report NC-212; U.S. Dept. of Agriculture, Forest Service, North Central Forest Experiment Station: St. Paul, MN, USA, 2000; pp. 176-184.

3. Mathys, L.; Ginzler, C.; Zimmermann, E.; Brassel, P.; Wildi, O. Sensitivity assessment on continuous landscape variables to classify a discrete forest area. For. Ecol. Manag. 2006, 229, 111-119. [CrossRef]

4. Colson, F.; Bogaert, J.; Filho, A.C.; Nelson, B.; Pinage, E.R. The influence of forest definition on landscape fragmentation assessment in Rondônia, Brazil. Ecol. Indic. 2009, 9, 1163-1168. [CrossRef] 
5. Seebach, L.M.; Strobl, P.; San Miguel-Ayanz, J.; Gallego, J.; Bastrup-Birk, A. Comparative analysis of harmonized forest area estimates for European countries. Int. J. For. Res. 2011, 84, 285-299. [CrossRef]

6. Romijn, E.; Ainembabazi, J.H.; Wijaya, A.; Herold, M.; Angelsen, A.; Verchot, L.; Murdiyarso, D. Exploring different forest definitions and their impact on developing REDD+ reference emission levels: A case study for Indonesia. Environ. Sci. Policy 2013, 33, 246-259. [CrossRef]

7. Sasaki, N.; Putz, F.E. Crucial need for new definitions of "forest" and "forest degradation" in global climate change agreements. A J. Soc. Conserv. Biol. 2009, 2, 226-232.

8. Mayeux, P.; Frederic, A.; Malingeau, J.P. Global tropical forest area measurements derived from coarse resolution satellite imagery: A comparison with other approaches. Environ. Conserv. 1998, 25, 37-52. [CrossRef]

9. FAO. Global Forest Resources Assessment Update 2005, Terms and Definitions. In Forest Resources Assessment (2004) Working Paper 83; FAO: Rome, Italy, 2005.

10. FAO. Specification of National Reporting Tables for FRA 2010. In Forest Resources Assessment (2007) Working Paper 135; FAO: Rome, Italy, 2010.

11. FAO. Forest Resources Assessment Update 2015, Terms and Definitions. In Forest Resources Assessment (2012) Working Paper 180; FAO: Rome, Italy, 2015.

12. Decision 2/CMP.7. Land use, land-use change and forestry (2012). In Proceedings of the Report of the Conference of the Parties serving as the meeting of the Parties to the Kyoto Protocol on Its Seventh Session, Durban, South African, 28 November-11 December 2011.

13. Jabłoński, M. Definicja lasu w ujęciu krajowym i międzynarodowym oraz jej znaczenie dla wielkości i zmian powierzchni lasów w Polsce. Sylwan 2015, 159, 469-482.

14. Jabłoński, M. Powierzchnia lasów. Definicja definicji nierówna. Las Pol. 2015, 24, 24-26.

15. Jabłoński, M. Powierzchnia gruntów leśnych-Przyczyny zmian i spójność źródeł danych. Wiadomości Stat. 2015, 11, 54-68.

16. Jabłoński, M.; Korhonen, K.T.; Budniak, P.; Mionskowski, M.; Zajaczkowski, G.; Sućko, K. Comparing land use registry and sample based inventory to estimate forest area in Podlaskie, Poland. iForest 2017, 10, 315-321. [CrossRef]

17. Neef, T.; von Luepke, H.; Schoene, D. Choosing a Forest Definition for the Clean Development Mechanism; FAO: Rome, Italy, 2006; pp. $1-18$.

18. Próchnicki, P. Wykorzystanie GIS i teledetekcji jako narzędzi do analizy sukcesji zakrzewień w Narwiańskim Parku Narodowym. Rocz. Geomatyki 2006, 4, 127-134.

19. Kunz, M.; Nienartowicz, A.; Deptuła, M. Teledetekcja satelitarna wtórnych lasów na gruntach porolnych na przykładzie Zaborskiego Parku Krajobrazowego. Fotointerpret. W Geogr. 2000, 31, 122-128.

20. Haapanen, R.; Ek, A.R.; Bauer, M.E.; Finley, E.O. Delineation of forest/non forest land use classes using nearest neighbor methods. Remote Sens. Environ. 2004, 89, 265-271. [CrossRef]

21. McRoberts, R.E. Satellite image-based maps: Scientific inference or pretty pictures. Remote Sens. Environ. 2011, 115, 715-724. [CrossRef]

22. McRoberts, R.E.; Gobakken, T.; Naesset, E. Post-stratified estimation of forest area and growing stock volume using lidar-based stratifications. Remote Sens. Environ. 2012, 125, 157-166. [CrossRef]

23. Stehman, S.V.; Foody, G.M. Key issues in rigorous accuracy assessment of land cover products. Remote Sens. Environ. 2019, 231, 111199. [CrossRef]

24. Stehman, S.V. Estimating area from an accuracy assessment error matrix. Remote Sens. Environ. 2013, 132, 202-211. [CrossRef]

25. Olofsson, P.; Foody, G.M.; Herold, M.; Stehman, S.V.; Woodcock, C.E.; Wulder, M.A. Good practices for estimating area and assessing accuracy of land change. Remote Sens. Environ. 2014, 148, 42-57. [CrossRef]

26. Naesset, E.; Orka, H.O.; Solberg, S.; Bollandsas, O.M.; Hansen, E.H.; Mauya, E.; Zahabu, E.; Malimbwi, R.; Chamuya, N.; Olsson, H.; et al. Mapping and estimating forest area and aboveground biomass in miombo woodlands in Tanzania using data from airborne. Remote Sens. Environ. 2016, 175, 282-300. [CrossRef]

27. Wang, Z.; Boesch, R.; Ginzler, C. Integration of high resolution aerial images and airborne Lidar data for forest delineation. In Proceedings of the International Archives of the Photogrammetry, Remote Sensing and Spatial Information Sciences 37 (B7), Beijing, China, 3-11 July 2008.

28. Wang, Z.; Boesch, R.; Ginzler, C. Color and LiDAR data fusion: Application to automatic forest boundary delineation in aerial images. Int. Arch. Photogramm. Remote Sens. Spat. Inf. Sci. 2007, 3, 1203-1207.

29. Wang, Z.; Boesch, R.; Ginzler, C. Aerial images and LIDAR Fusion Applied in Forest Boundary. In Proceedings of the 7th WSEAS International Conference on Signal, Speech and Image Processing, Beijing, China, 15-17 September 2007.

30. Pekkarinen, A.; Reithmaier, L.; Strobl, P. Pan-European forest/non-forest mapping with Landsat ETM+ and CORINE Land Cover 2000 data. J. Photogramm. Remote Sens. 2009, 64, 171-183. [CrossRef]

31. Hościłło, A.; Mirończuk, A.; Lewandowska, A.; Gasiorowski, J. Inventory of the Actual Forest Cover of the Country Using the Existing Photogrammetric Data; Institute of Geodesy and Cartography: Warsaw, Poland, 2015.

32. Thompson, S.D.; Nelson, T.A.; Giesbrecht, I.; Frazer, G.; Saunders, S.C. Data-driven regionalization of forested and non-forested ecosystems in coastal British Columbia with LiDAR and RapidEye imagery. Appl. Geogr. 2016, 69, 35-50. [CrossRef]

33. Wężyk, P.; de Kok, R. Automatic Mapping of the Dynamics of Forest Successionon Abandoned Parcels in South Poland. Angezw. Geoinformatik 2005, 1-6. 
34. Kolecka, N.; Kozak, J.; Kaim, D.; Dobosz, M.; Ginzler, C.; Psomas, A. Mapping Secondary Forest Succession on Abandoned Agricultural Land with LiDAR Point Clouds and Terrestrial Photography. Remote Sens. 2015, 7, 8300-8322. [CrossRef]

35. Szostak, M.; Hawryło, P.; Piela, P. Using of Sentinel-2 images for automation of the forest succession detection. Eur. J. Remote Sens. 2018, 51, 142-149. [CrossRef]

36. Pujar, G.S.; Reddy, P.M.; Reddy, C.S.; Jha, C.S.; Dadhwal, V.K. Estimation of Trees Outside Forests using IRS High Resolution data by Object Based Image Analysis. In Proceedings of the International Archives of the Photogrammetry, Remote Sensing and Spatial Information Sciences XL-8, Hyderabad, India, 9-12 December 2014; pp. 623-629.

37. Castillo-Núñez, M.; Sánchez-Azofeifa, A.; Croitoru, A.; Rivard, B.; Calvo-Alvarado, J.; Dubayah, R.O. Delineation of secondary succession mechanisms for tropical dry forests using LiDAR. Remote Sens. Environ. 2011, 115, 2217-2231. [CrossRef]

38. Vega, C.; Durrieu, S. Multi-level filtering segmentation to measure individual tree parameters based on Lidar data: Application to a mountainous forest with heterogeneous stands. Int. J. Appl. Earth Obs. Geoinf. 2011, 13, 646-656. [CrossRef]

39. Vega, C.; Hamrouni, A.; El Mokhtari, S.; Morel, J.; Bock, J.; Renaud, J.-P.; Bouvier, M.; Durrieu, S. PTrees: A point-based approach to forest tree extraction from lidar data. Int. J. Appl. Earth Obs. Geoinf. 2014, 33, 98-108. [CrossRef]

40. Swetnam, T.L.; Falk, D.A. Application of Metabolic Scaling Theory to reduce error in local maxima tree segmentation from aerial LiDAR. For. Ecol. Manag. 2014, 323, 158-167. [CrossRef]

41. Strimbu, V.F.; Strimbu, B.M. A graph-based segmentation algorithm for tree crown extraction using airborne LiDAR data. ISPRS J. Photogramm. Remote Sens. 2015, 104, 30-43. [CrossRef]

42. Latifi, H.; Fassnacht, F.E.; Muller, J.; Tharani, A.; Dech, S.; Heurich, M. Forest inventories by LiDAR data: A comparison of single tree segmentation and metric-based methods for inventories of a heterogeneous temperate forest. Int. J. Appl. Earth Obs. Geoinf. 2015, 42, 162-174. [CrossRef]

43. Mongus, D.; Zalik, B. An efficient approach to 3D single tree-crown delineation in LiDAR data. ISPRS J. Photogramm. Remote Sens. 2015, 108, 219-233. [CrossRef]

44. Ferraz, A.; Saatchi, S.; Mallet, C.; Meyer, V. Lidar detection of individual tree size in tropical forests. Remote Sens. Environ. 2016, 183, 318-333. [CrossRef]

45. Hamraz, H.; Contrares, M.A.; Zhang, J. A scalable approach for tree segmentation within small-footprint airborne LiDAR data. Comput. Geosci. 2017, 102, 139-147. [CrossRef]

46. Hamraz, H.; Contrares, M.A.; Zhang, J. A robust approach for tree segmentation in deciduous forests using small-footprint airborne LiDAR data. Int. J. Appl. Earth Obs. Geoinf. 2016, 52, 532-541. [CrossRef]

47. Wu, B.; Yu, B.; Wu, Q.; Huang, Y.; Chen, Z.; Wu, J. Individual tree crown delineation using localized contour tree method and airborne LiDAR data in coniferous forests. Int. J. Appl. Earth Obs. Geoinf. 2016, 52, 82-94. [CrossRef]

48. Kamińska, A.; Lisiewicz, M.; Stereńczak, K.; Kraszewski, B.; Sadkowski, R. Species-related single dead tree detection using multi-temporal ALS data and CIR imagery. Remote Sens. Environ. 2018, 219, 31-43. [CrossRef]

49. Magdon, P.; Kleinn, C. Uncertainties of forest area estimates caused by the minimum crown cover criterion-a scale issue relevant to forest cover monitoring. Environ. Monit. Assess. 2013, 185, 5345-5360. [CrossRef] [PubMed]

50. Eysn, L.; Hollaus, M.; Schadauer, K.; Pfeifer, N. Forest Delineation Based on Airborne LIDAR Data. Remote Sens. 2012, 4, 762-783. [CrossRef]

51. Eysn, L.; Hollaus, M.; Schadauer, K.; Pfeifer, N.; Roncat, A. Crown coverage calculation based on ALS data. In Proceedings of the 11th International Conference on LiDAR Applications for Assessing Forest Ecosystems-SilviLaser 2011, Hobart, Australia, 16-20 October 2011.

52. Eysn, L.; Hollaus, M.; Vetter, M.; Mücke, W.; Pfeifer, N.; Regner, B. Adapting alpha-shapes for forest delineation using ALS Data. In Proceedings of the 10th International Conference on LiDAR Applications for Assessing Forest Ecosystems-Silvilaser 2010, Freiburg, Germany, 14-17 September 2010.

53. Sackov, I.; Kardos, M. Forest delineation based on LiDAR data and vertical accuracy of the terrain model in forest and non-forest area. Ann. For. Res. 2014, 57, 119-136. [CrossRef]

54. Straub, C.; Weinacker, H.; Koch, B. A fully automated procedure for delineation and classification of forest and non-forest vegetation based on full waveform laser scanner data. In Proceedings of the International Archives of the Photogrammetry, Remote Sensing and Spatial Information Sciences 37 (B8), Beijing, China, 3-11 July 2008.

55. Szwagrzyk, J. Sukcesja leśna na gruntach porolnych; stan obecny, prognozy i watpliwości. Sylwan 2017, 4, 53-59.

56. Milicz Forest District Website. Available online: https:/ / milicz.wroclaw.lasy.gov.pl (accessed on 16 March 2020).

57. Stereńczak, K.; Lisańczuk, M.; Parkitna, K.; Mitelsztedt, K.; Mroczek, P.; Miścicki, S. The influence of number and size of sample plots on modelling growning stock volume based on airborne laser scanning. Drewno 2018, 61, 5-22.

58. Stereńczak, K.; Kraszewski, B.; Mielcarek, M.; Piasecka, Ż.; Lisiewicz, M.; Heurich, M. Mapping individual trees with airborne laser scanning data in an European lowland forest using a self-calibration algorithm. Int. J. Appl. Earth Obs. Geoinf. 2020, 93, 102191. [CrossRef]

59. Mielcarek, M.; Kamińska, A.; Stereńczak, K. Digital Aerial Photogrammetry (DAP) and Airborne Laser Scanning (ALS) as Sources of Information about Tree Height: Comparisons of the Accuracy of Remote Sensing Methods for Tree Height Estimation. Remote Sens. 2020, 12, 1808. [CrossRef] 
60. Ciesielski, M.; Stereńczak, K. Volunteered Geographic Information data as a source of information on the use of forests in the Warsaw agglomeration. Sylwan 2020, 164, 695-704.

61. Ciesielski, M.; Stereńczak, K. What do we expect from forests? The European view of public demands. J. Environ. Manag. 2018, 209, 139-151. [CrossRef] [PubMed] 